\title{
Additive manufacturing towards product production: a bibliometric analysis
}

\author{
Thywill Cephas Dzogbewu ${ }^{1, *}$ (D), Nathaniel Amoah ${ }^{2}$ (D), Samuel Korateng Fianko ${ }^{3}$, Sampson Afrifa Jnr ${ }^{3}$ (D), \\ and Deon de Beer ${ }^{4}$ \\ ${ }^{1}$ Department of Mechanical and Mechatronics Engineering, Central University of Technology, Free State, South Africa \\ 2 Department of Business \& Law, Universita degli Studi di Brescia, Italy \\ ${ }^{3}$ Department of Business Support Studies, Central University of Technology, Free State, South Africa \\ ${ }^{4}$ Centre for Rapid Prototyping and Manufacturing, Faculty of Engineering, Built Environment and Information Technology, \\ Central University of Technology, Free State, Bloemfontein 9301, South Africa
}

Received: 14 October 2021 / Accepted: 7 December 2021

\begin{abstract}
Additively manufactured products offer extensive variety to consumers than many forms of production. Additive manufacturing (AM) production system allows consumer involvement, which has created a huge but largely untapped market. However, there is a gap between production and the market. Therefore, AM towards product production which focuses on the Commercialization of Additive Manufactured Products (CAMPs) is imperative. Despite the importance of CAMP, specific focus of research on the commercialization of additively manufactured products are scanty. There is also a lack of knowledge about the conceptual structure, intellectual structure, research trends, and the thematic structure of CAMP research. To contribute to this stream of research, this study takes an exploratory dimension by conducting a bibliometric analysis of publications on the CAMP. The R package and its associated biblioshiny were the software used. The study reveals that studies on CAMP started in 2007 with renewed interest starting from 2012. Importantly, it was found that the most cited articles focused on the economic potential of AM products in the home and specific industries. Also, there is an increasing focus on the business models that are necessary for the commercialisation of AM products. Generally, there is a shift in focus from the firm to the market. However, this is a niche area and requires more attention. Themes such as commercialization are just emerging, and researchers need to devote more time and effort to the consumer side of the commercialization of AM products.
\end{abstract}

Keywords: Commercialization / 3D printing / additive manufacturing / bibliometrics / intellectual structure / conceptual structure / content analysis / market

\section{Introduction}

Additive manufacturing towards product production is the commercialization of Additive manufactured products. Additive manufacturing (AM) which is generally referred to as $3 \mathrm{D}$ printing belongs to a group of technologies that use a computer-generated model to create a three-dimensional (3D) object based on the information provided by a computerized program [1]. It is a paradigm shift from the conventional subtractive methods (casting, forging, sheet forming, extrusion, etc.) of manufacturing [2]. Additive manufacturing joined materials together layer-by-layer monolithically as opposed to subtractive manufacturing approach of the conventional methods [3]. AM builds

\footnotetext{
* e-mail: thydzo@yahoo.fr
}

components from different ranges of metals, plastics and ceramics with intricated geometries for tailored engineering or biological applications [4]. These materials are made available in powder form, liquid form, sheets, filaments or ribbons. Over the years, the application of AM has shifted from a rapid prototyping technology to a manufacturing technology for end-user production [5]. Since then, it has demonstrated remarkable success in manufacturing 3D objects with intricate structures with ease in a variety of industries, including aerospace, automotive, education and pharmaceutical [6]. In the medical and pharmaceutical industries, for instance, AM processes were used to create complex structures such as scaffolds, and patient-specific implants with tailored geometrical configurations [7].

Since the inception of AM technology over three decades ago, the market for AM technology has continuously evolved and gained popularity [8]. It is reported that 
the total global revenues from AM products surpasses $\$ 6$ billion in 2016, a rise of 17.4 percent in the industry [9]. In 2020 the AM market was globally estimated at 13.78 billion dollars. From 2021 to 2028, the worldwide AM market is predicted to develop at a compound yearly growth rate of $21 \%$ [10]. It is also forecasted that the shipment of AM machines across the globe will rise in units of about 15.3 million from the 2.1 million units that was recorded in 2020 . The expansion of the AM market was fueled by the aggressive research and development in AM technology, as well as the rising demand for AM technology in many sectors of the economy. According to Gerstle et al. [8], half of all globally manufactured products will be produced using AM technology by 2060 if the current investment in AM technology continues.

The AM technology permits the manufacturing of 3D conceptualised objects in one manufacturing cycle directly, from digital data resulting in a reduction in time for completing product development cycles [2]. The AM technology is considered as a renaissance of the manufacturing industry, and it has the capability to produce 3D objects monolithically with complex geometries which is almost impossible to produce using the conventional methods of manufacturing [3]. There are different types of AM manufacturing technologies that are used to print different materials (metals, polymers, ceramics, composites, foods, textiles, etc. [11] The American Society for Testing and Materials (ASTM) international committee F42 on AM technologies classified the AM manufacturing technology into seven categories, namely: powder bed fusion, directed energy deposition, sheet lamination, photopolymer vat, material extrusion, material jetting, and binder jetting [12]. Each of these technologies has its unique application/s and can print different material/s with different printing mechanisms $[2,11,13-15]$ and with a certain degree of geometrical accuracy [2]. For example, powder bed fusion, directed energy deposition, and sheet lamination can be used to print metallic feedstocks (powder particles, sheets, wires). However, powder bed fusion manufacturing systems are typically employed to produce intricate geometries requiring high resolution and rigorous build accuracy, while directed energy deposition systems are commonly applied to repair and refurbish metal parts and for large-scale manufacturing [16]. Sheet lamination systems have the capability of joining dissimilar metals to produce components with some specific properties [15]. Material extrusion, material jetting, and binder jetting can be used to print ceramics, polymers and composites [11]. It is worth mentioning that, AM technology is a powerful tool that is currently used to provide customized medical equipment to fight the covid-19 pandemic [17]. Due to its freedom of design, it is used to improvised many medical devices as covid-19 has disrupted the supply chain around the globe [18]. Using 3D printing technology currently to provide tailored medical equipment for specific clinical applications has demonstrated the superior manufacturing capabilities of AM technology as compared to the conventional methods of manufacturing.
The versatility demonstrated by AM technologies of producing $3 \mathrm{D}$ objects with near-net-shape resulting in a weight reduction, improve performance and efficiency has brought about significant evolutions and transformations in the manufacturing sector [19]. The AM methods are considered to have a competitive advantage over the traditional methods since they are perceived to enhance productivity vis a vis ensuring the sustainability of the environment [4]. Due to the above mentioned unique characteristics of the AM process, there is a progressive ongoing research of gaining in-depth understanding of the AM processes [20]. This is because, AM process involves various guidelines from CAD design, machine set-up, material sections, process parameters determination etc. Spears and Gold reported [21] that there are over 50 process parameters that govern the AM process which needs to be understood to obtain 3D objects with optimum mechanical properties. The complexities and technicalities of each stage differ based on the specific additive manufacturing process and the type of material involved [22]. The attempt to solve these problems have shifted the attention of the research community to the engineering aspect of the technology neglecting its commercialization dimensions [4]. Liu and Rong [23] reported that the 3D printing sector is yet to have any strategic and profitable entrepreneurship models, supportive ecosystems and stakeholders to enhance its commercialization. Other researchers stated that, although 3D printing technology has a competitive advantage over traditional manufacturing due to its greater flexibility and customization, its main challenge is research on its commercialization [24,25]. As a result, there are numerous publications on additive manufactured products however, specific research that focuses on the commercialization of AM products are scanty. Unfortunately, the conceptual structure, intellectual structure, research trends, and thematic structure of the field has seen little or no exploration yet. To offer an understanding of the nature of commercialization of additive manufactured products (CAMPs) research, this study conducts a bibliometric analysis of publications on CAMP. This is done to examine what has already been done and also provide direction for future studies.

Pritchard [26] defines bibliometrics as "the mathematical and statistical analysis of bibliographic records". It includes a variety of techniques that are usually categorised as citation or co-citation analysis. Hoffman and Holbrook [27] provide a helpful overview and discussion of these various methods. The direct counts of references made to or received from other documents are used in citation analysis. Co-citation analysis, on the other hand, uses paired citations as a measure of association between documents or groups of documents. Bibliographic coupling, document co-citation analysis, author co-citation analysis, and co-word analysis are some of the methods used in co-citation analysis [28].

The discovery of intellectual linkages among (scholarly) communications and the creation of science maps are two 
of its most important applications. Document co-citation links documents based on the number of identical citing articles, whereas bibliographic coupling links documents that share identical references. Small [29] popularised the co-citation approach and advocated for its use to study the "specialty structure of science" in one of his early works. Since then, co-citation analysis has become widely used in a variety of disciplines. While bibliometric analysis has been shown to be useful in a variety of fields, it is hard to come by any bibliometric studies on CAMP. Even though CAMP has been studied for more than a decade, there are many unanswered questions about its domain and scope. The current research draws on the body of academic literature to uncover the field's hidden structure. It also provides information on some of the major publishing houses, as well as a benchmark for further research into trends and emerging paradigms in CAMP.

Objective 1: To identify the number of publications on commercialization of additive manufactured products, including an analysis of the authors, institutions, and nations that publish the most articles on the commercialization of additive manufactured products.

Objective 2: To analyse the thematic network of studies on the commercialization of additive manufactured products.

Objective 3: To analyse the conceptual map of studies on the commercialization of additive manufactured products.

Objective 4: To examine the intellectual structure of studies on the commercialization of additive manufactured products.

\section{Materials and methods}

To answer the research questions and provide an accurate representation of the state of the literature on commercialization of additive manufactured products (CAMP) and collaborative activities in the process of CAMP research, a two-tier analysis that included bibliometric analysis of articles collected from the Web of Science and Scopus databases, as well as cluster analysis, were conducted.

\subsection{Selection of citation index}

Following Bartolini et al. [30] and Zhang et al. [31], this review was undertaken using data from two databases: Clarivate Analytics' Web of Science (WoS) and Elsevier's Scopus. It was critical to consider more than one database, regardless of the scope of effect and coverage of a single database, because this broadens the scope of the study and increases the reliability of the outcome. Zhu and Liu [32] describe the two databases as the "two world-leading and competing databases". Web of Science, an independent global citation database, is regarded as the world's most reputable publisher [33]. While Scopus is considered as the world's largest database of peer-reviewed literature, it also includes novels, scientific journals, and conference proceedings. Scopus provides a comprehensive and insightful overview of the world's scientific research output, encompassing subjects such as science, technology, medicine, social sciences, and the arts and humanities [34]. Both databases are interdisciplinary in nature.

\subsection{Selection of keywords}

Keywords are required to identify all relevant papers in databases [35]. Conducting a keyword search on peer-reviewed journal publications related to the issue in question is one way to solve the problem of narrowing down to the specific literature required. The authors considered the various synonyms for the key terms 'additive manufacturing' and 'commercialization' before deciding on the keywords. It was discovered that the British rendition 'commercialisation' is used instead of 'commercialization' in most British English-based journals. It was also noted that in some journals, words like "sales," "marketing," and "business model" were used instead of "commercialization," but the idea was the same. Hence the decision to add the three terminologies as keywords for the search. The use of the asterisk $\left(^{*}\right)$ in search expanded the search net to include terms that were similar but had different endings. The asterisk is a common wildcard symbol that allows you to broaden your search by looking for words that start with the same letters. It can be used to quickly find variants of a term when using unique word stems [36]. As a result, a term like' manufact*' would include words like' manufacturing," manufacture,' and' manufactured.' Furthermore, while some publications used the term "3D printing," others used the term "additive manufacturing," necessitating the use of both terminologies in the search, as well as variations and synonyms of the term "commercialization."The same keywords were used to search in both databases to ensure synchronicity. The following search string was used to gather data from WoS: "commercializ*" AND "3d print*" (Title) or "commercializ*" AND "additive manufact*" (Title) or "sale*" AND "3d print*" (Title) or "sale*" AND "additive manufact*" (Title) or "market*" AND "3d print*" (Title) or "market*" AND "additive manufact*" (Title) or "business model*" AND "3d print*" (Title) or "business model*" AND "additive manufact*" (Title)

Whilst the following was used for the search on Scopus (TITLE ("commercializ" AND "3d print*") OR TITLE ("commercializ" "AND "additive manufact*") OR TITLE ("sale*" AND "3d print*") OR TITLE ("sale*" AND "additive manufact*") OR TITLE ("market*" AND "3d print*") OR TITLE ("market*" AND "additive manufact*") OR TITLE ("business model*" AND "3d print*") OR TITLE ("business model*" AND "additive manufact*"))

\subsection{Data collection and processing}

Due to the limited number of publications related to the commercialization of additive manufactured products, no restrictions were set to the year range. However, the search 
Table 1. Data synthesis.

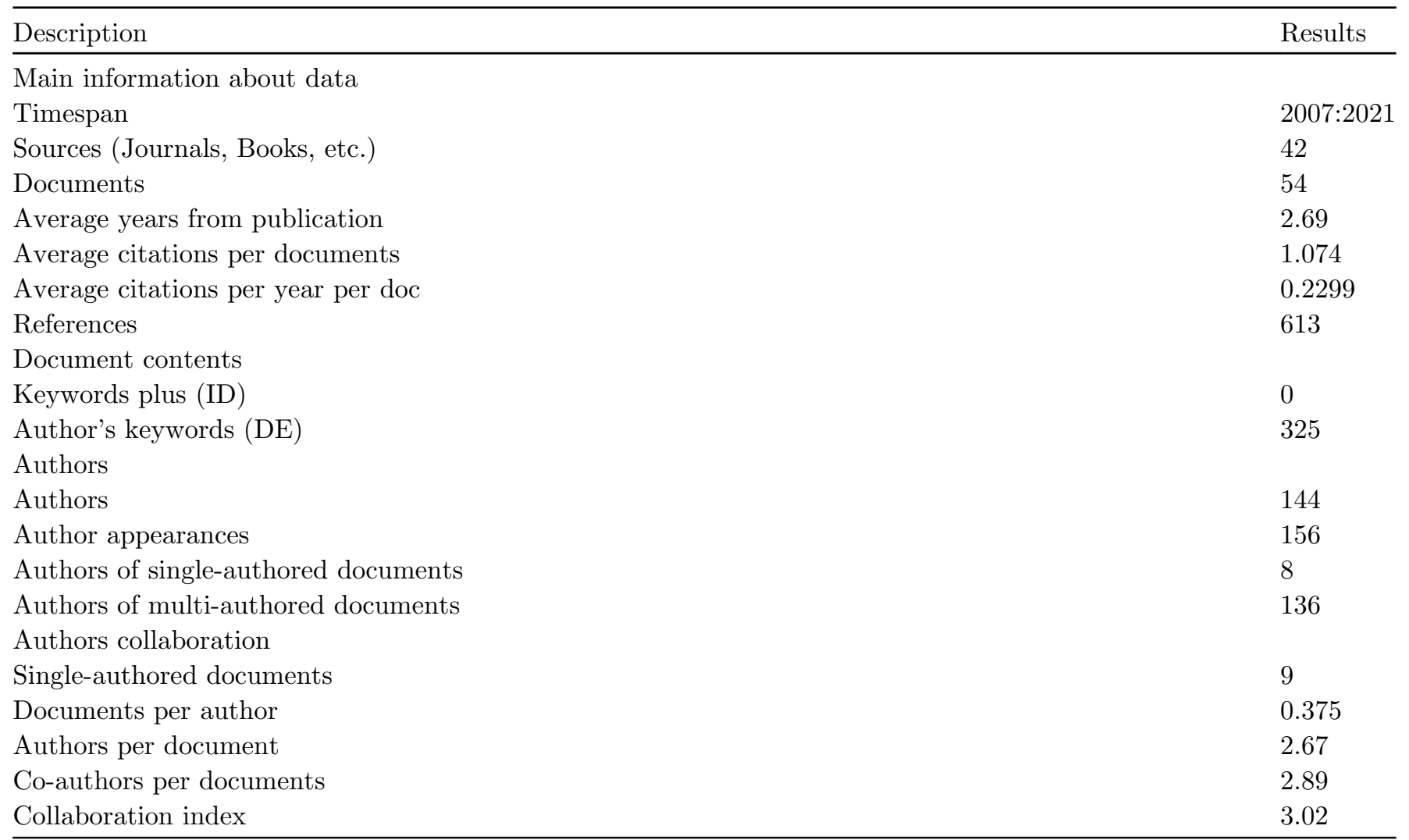

was restricted to articles and review papers and papers written in the English language. To emphasise, no time constraints were indicated because the review was meant to be as exploratory as possible and to examine the trends from the beginning of research on CAMP to date. However, to ensure specificity, only document titles were analysed. As a result, a total of 54 articles were obtained after duplicates were removed in the $\mathrm{R}$ package. Initially, 39 articles were obtained from WoS whilst 43 were realised from Scopus totalling 82 publications. 28 were removed as they were duplicated in both databases.

\subsection{Analysis process}

To gain insight into CAMP, a two-phase procedure was adopted. The study focused on two types of bibliometric indicators, (1) traditional bibliographical data such as authors, affiliations, sources (e.g., journal names), and publication year; and (2) terms (e.g., words and phrases) extracted from the titles and abstracts of research articles using natural language processing techniques. The $\mathrm{R}$ was used in both phases of the analysis. Clusters were also discovered at the second stage, which contributed to the selection of articles for the review's second phase. This was done to understand what the conceptual, social, and intellectual structure of the studies in the subject was like.

\subsection{Bibliometric analysis and software package}

The software bibliometrix R-package was utilised. The R package is an open-source software that includes several tools for conducting quantitative bibliometrics research. The R-package was produced by Aria and Cuccurullo and is written in the $\mathrm{R}$ programming language [37]. It includes the most essential statistical and scientific mapping algorithms. The web interface app (Biblioshiny) was added to recent versions of the bibliometrix R-package (i.e., 2.0 upwards) to assist users without the ability to code in the $\mathrm{R}$ language to develop output for bibliometric analyses. The Biblioshiny interface allows users to import data from Scopus or Web of Science databases in BibTex, CSV, or Plain Text format. Filtering data is also possible using Biblioshiny. The combined WoS and Scopus datasets were imported from the $\mathrm{R}$ package using the characteristics of biblioshiny for bibliometrix. The study's analysis is further described in the results section.

\section{Results}

\subsection{Data synthesis}

In this study, CAMP research was investigated by analysing the documents produced on the topic over the last one and a half decades [starting in 2007] and answering the following 


\section{Annual Scientific Production}

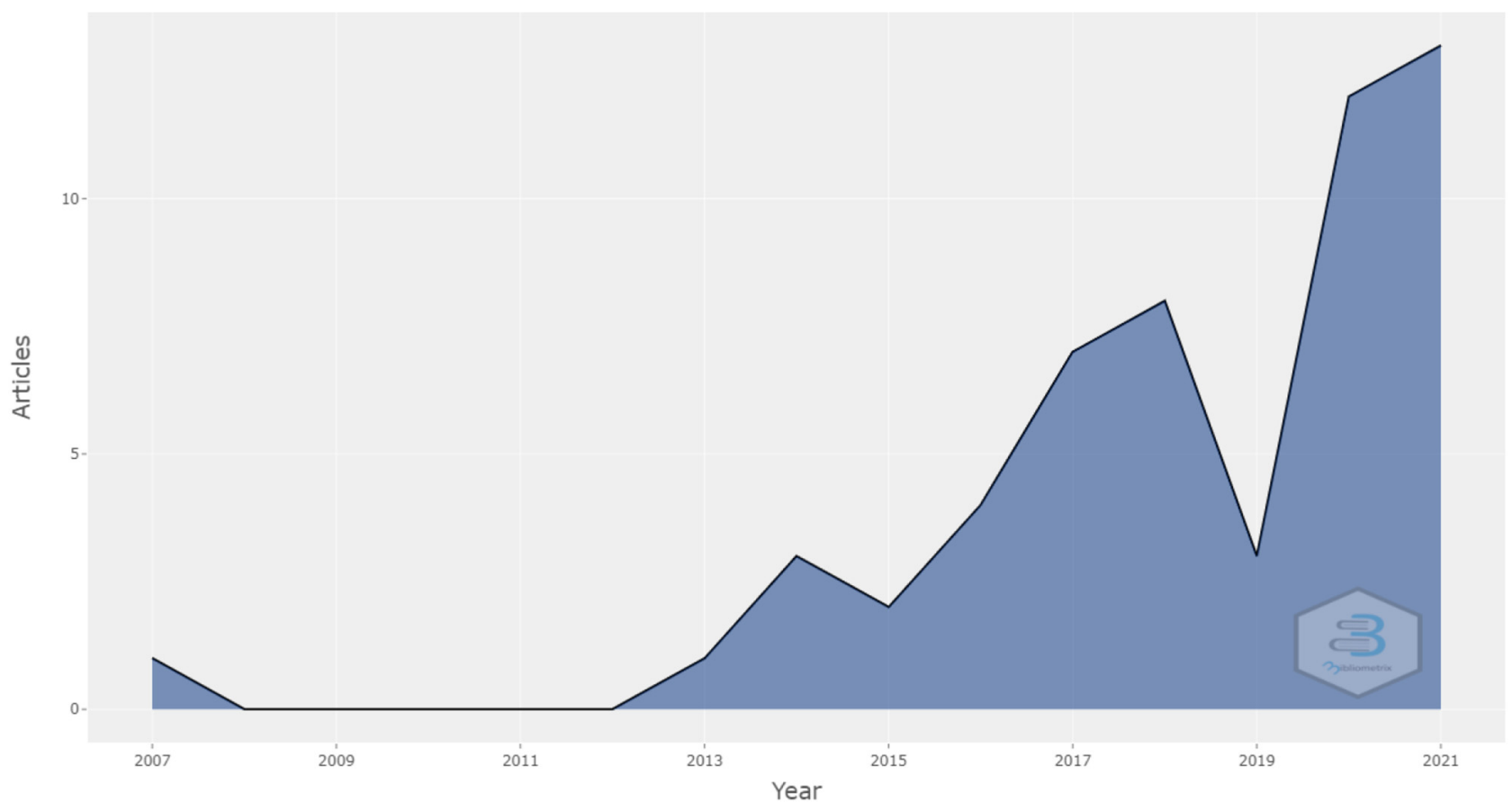

Fig. 1. Annual scientific production.

\section{Average Article Citations per Year}

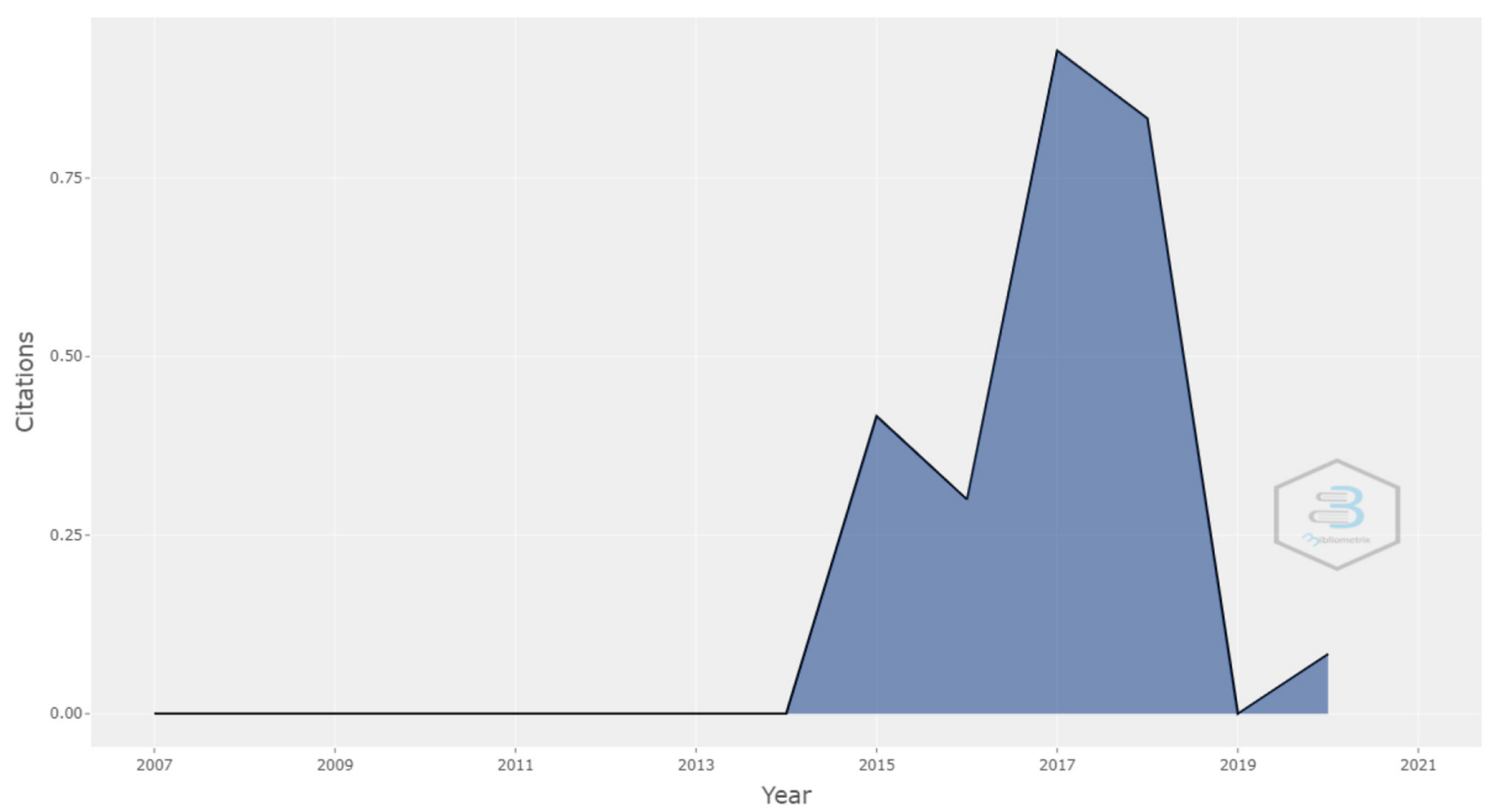

Fig. 2. Average citations per year. 
Most Relevant Sources

TECHNOLOGICAL FORECASTING AND SOCIAL CHANGE ADDITIVE MANUFACTURING

INTERNATIONAL JOURNAL OF PRODUCTION ECONOMICS JOURNAL OF MANUFACTURING TECHNOLOGY MANAGEMENT SUSTAINABILITY (SWITZERLAND) RAPID PROTOTYPING JOURNAL

3D PRINTING: LEGAL PHILOSOPHICAL AND ECONOMIC DIME ACTA ORTHOPAEDICA BELGICA

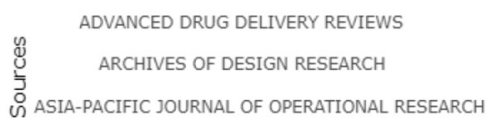
AUTOMATION IN CONSTRUCTION BMJ INNOVATIONS

ELECTROSPINNING: FROM BASIC RESEARCH TO COMMERCIAL INFORMATION SYSTEMS FRONTIERS

INTERNATIONAL JOURNAL OF AUTOMATION AND SMART TECH INTERNATIONAL JOURNAL OF E-ENTREPRENEURSHIP AND IN INTERNATIONAL JOURNAL OF PRECISION ENGINEERING AND INTERNATIONAL JOURNAL OF TECHNOLOGY MARKETING INTERNATIONAL JOURNAL ON FOOD SYSTEM DYNAMICS

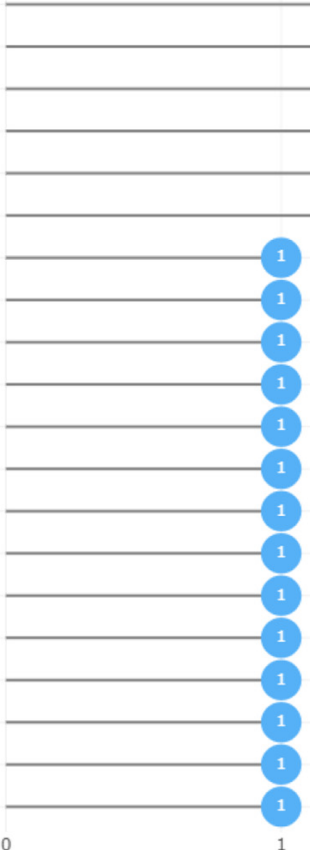

N. of Documents

Fig. 3. Most relevant sources.

\section{Source Growth}

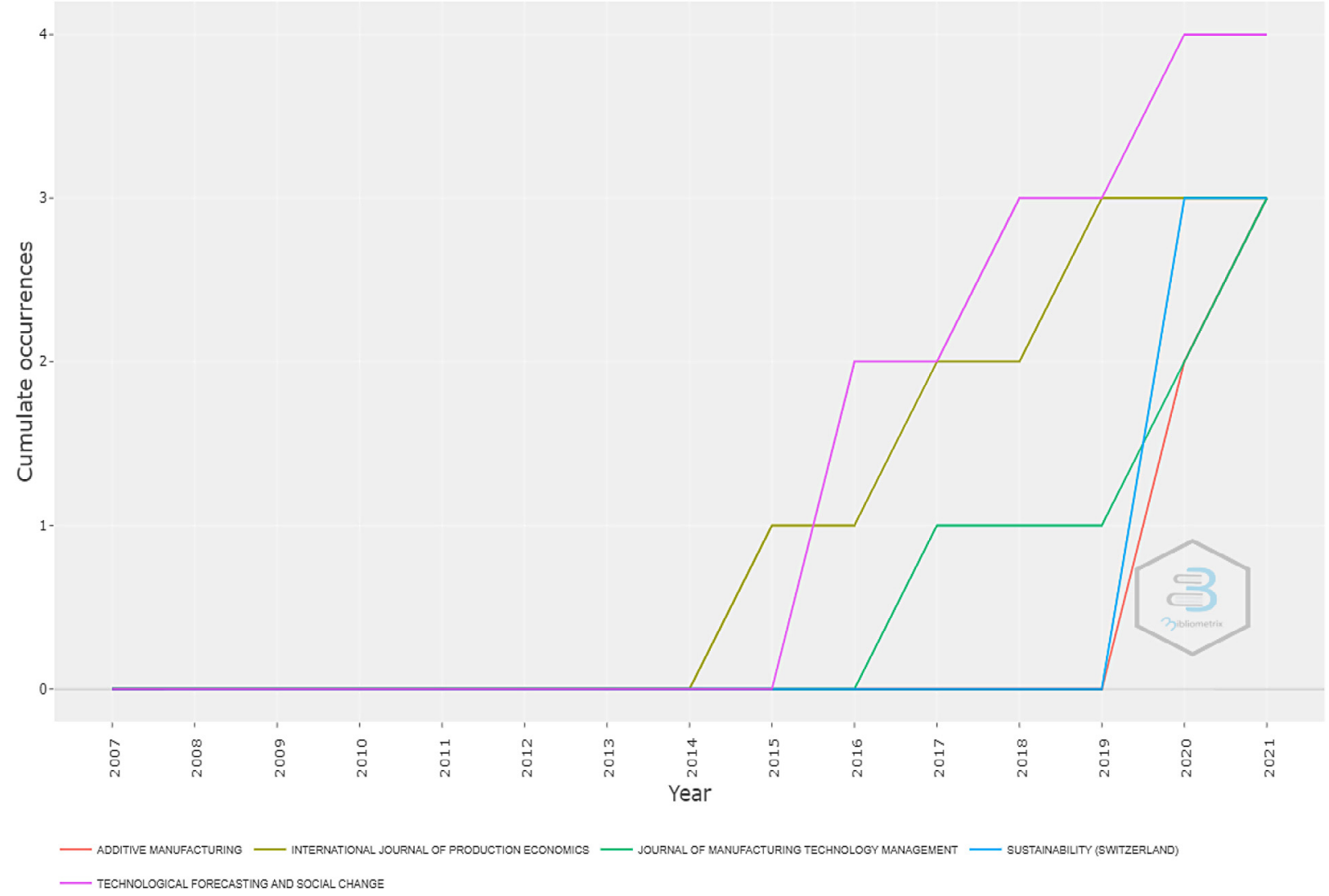

Fig. 4. Source growth. 


\section{Country Scientific Production}

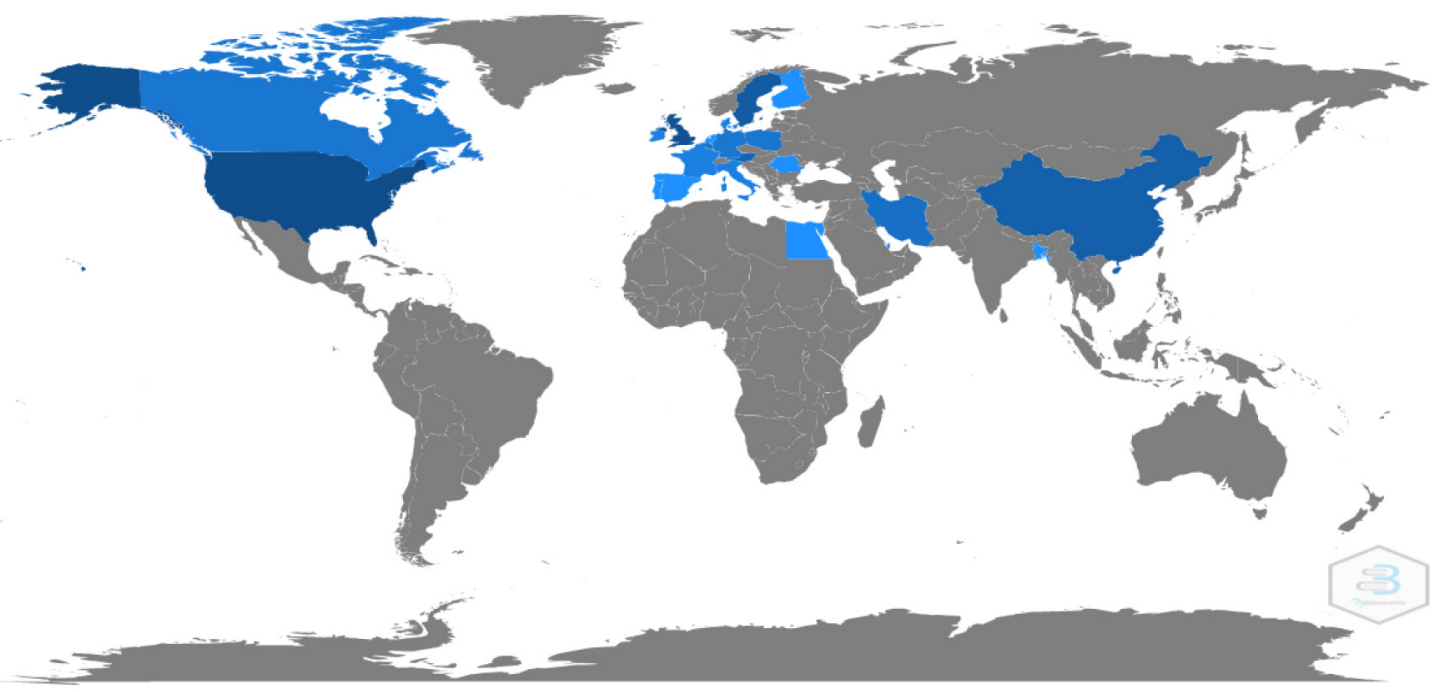

Fig. 5. Country specific production.

\section{Country Collaboration Map}

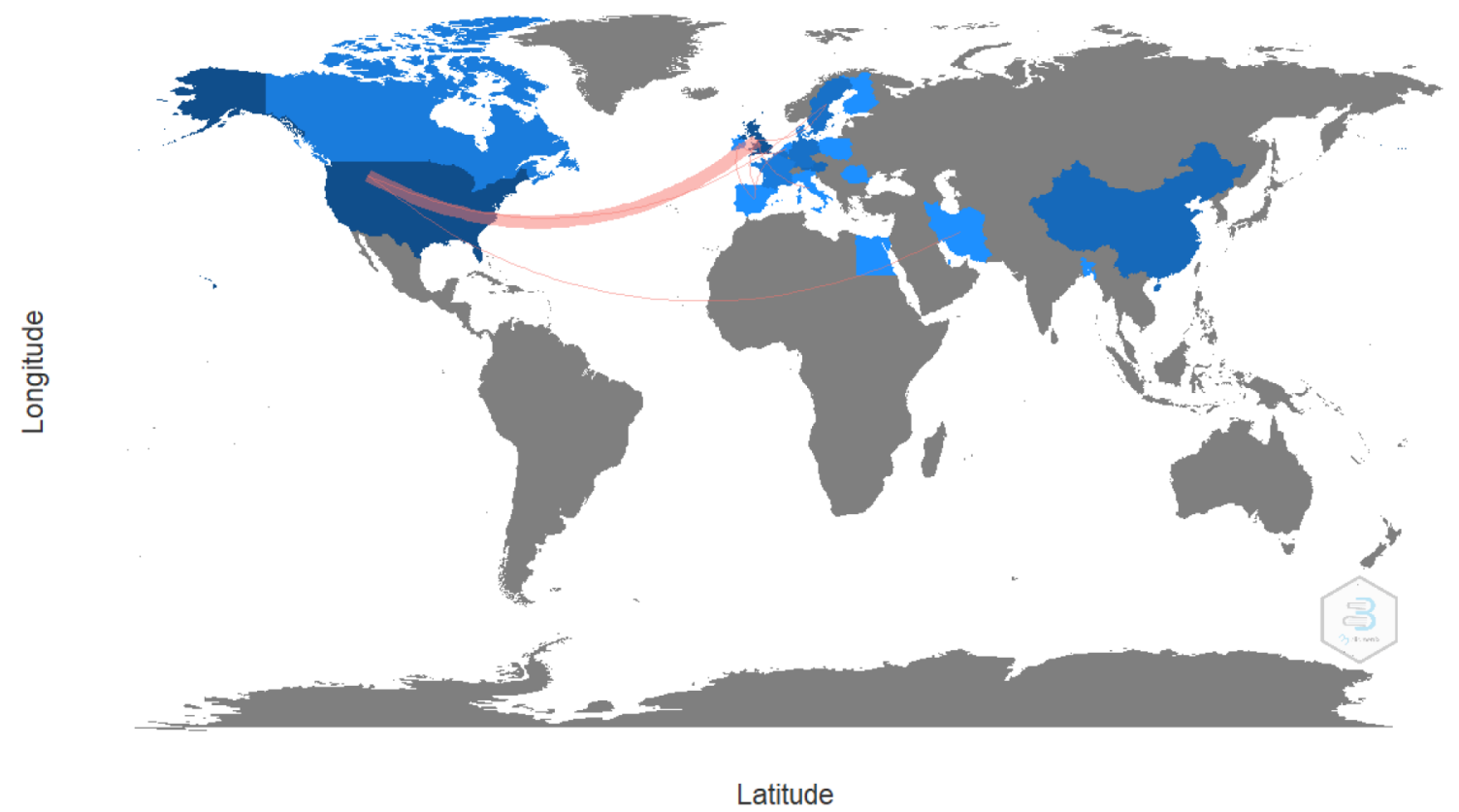

Fig. 6. Country collaboration map.

questions: Who are the major contributors to CAMP research (e.g., research institutes and universities, countries and regions, and research communities)? What is CAMP research's intellectual, conceptual and social structure? What has changed in CAMP research over time?
Table 1 shows the synthesised bibliometric analysis data. It offers a descriptive overview of the CAMP research. For the cluster analysis, the literature was thoroughly read, and the content was analysed by uncovering the connections between publications in the clusters. 


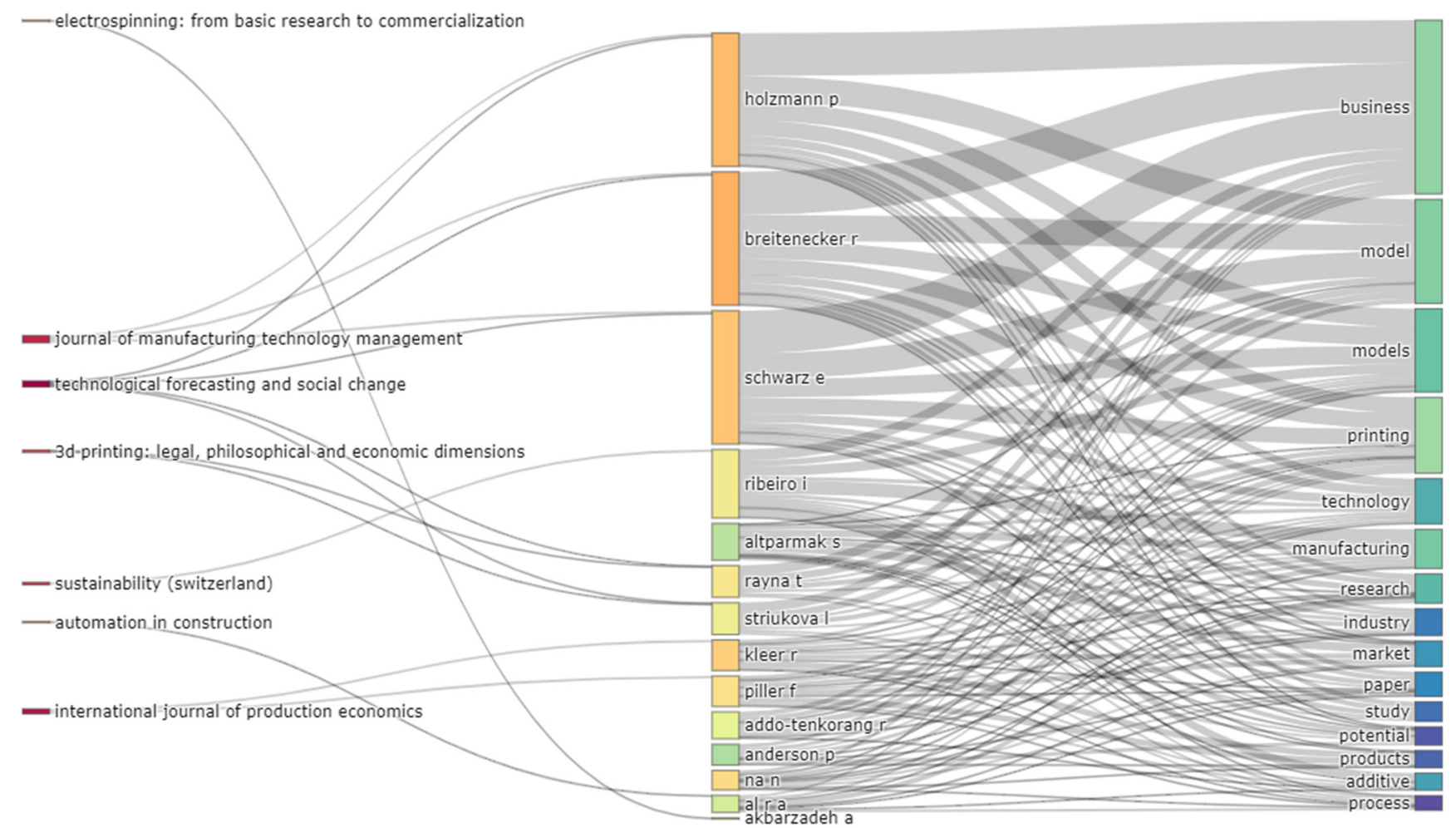

Fig. 7. Three-field plot of Journals, authors, and abstract keywords.

$2007-2019$

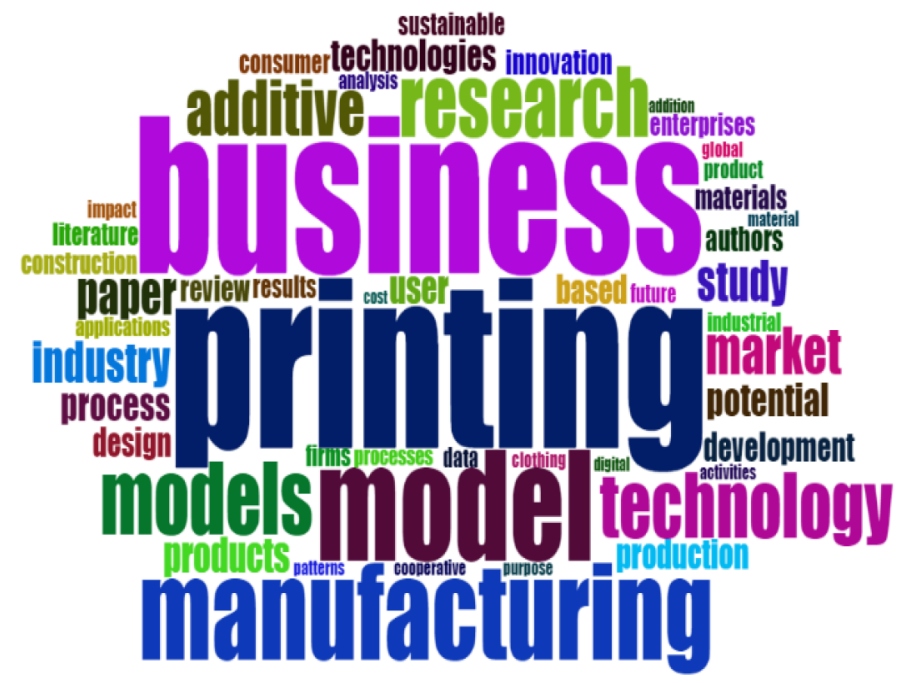

$2020-2021$

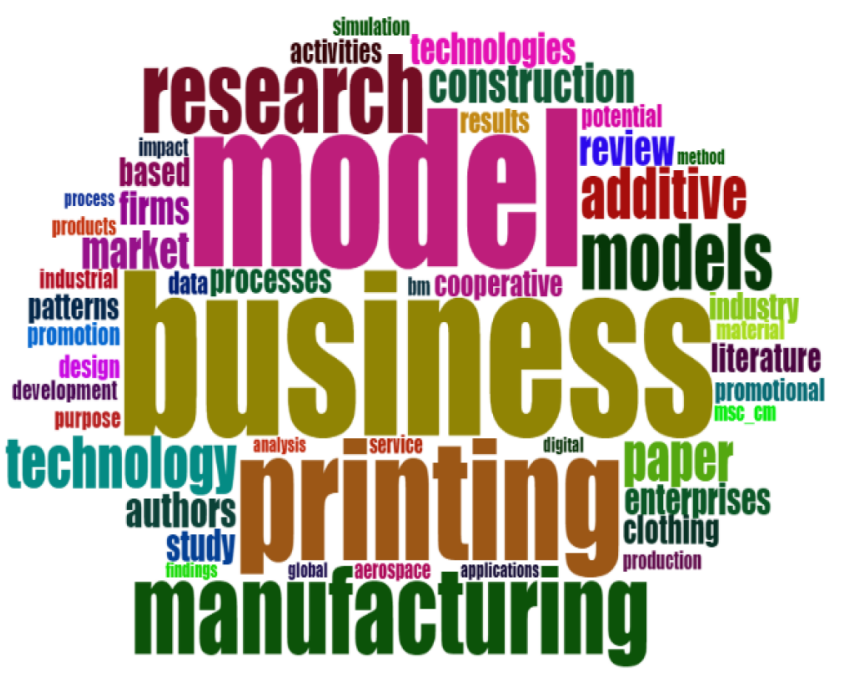

Fig. 8. Word cloud. 


\section{Word Growth}

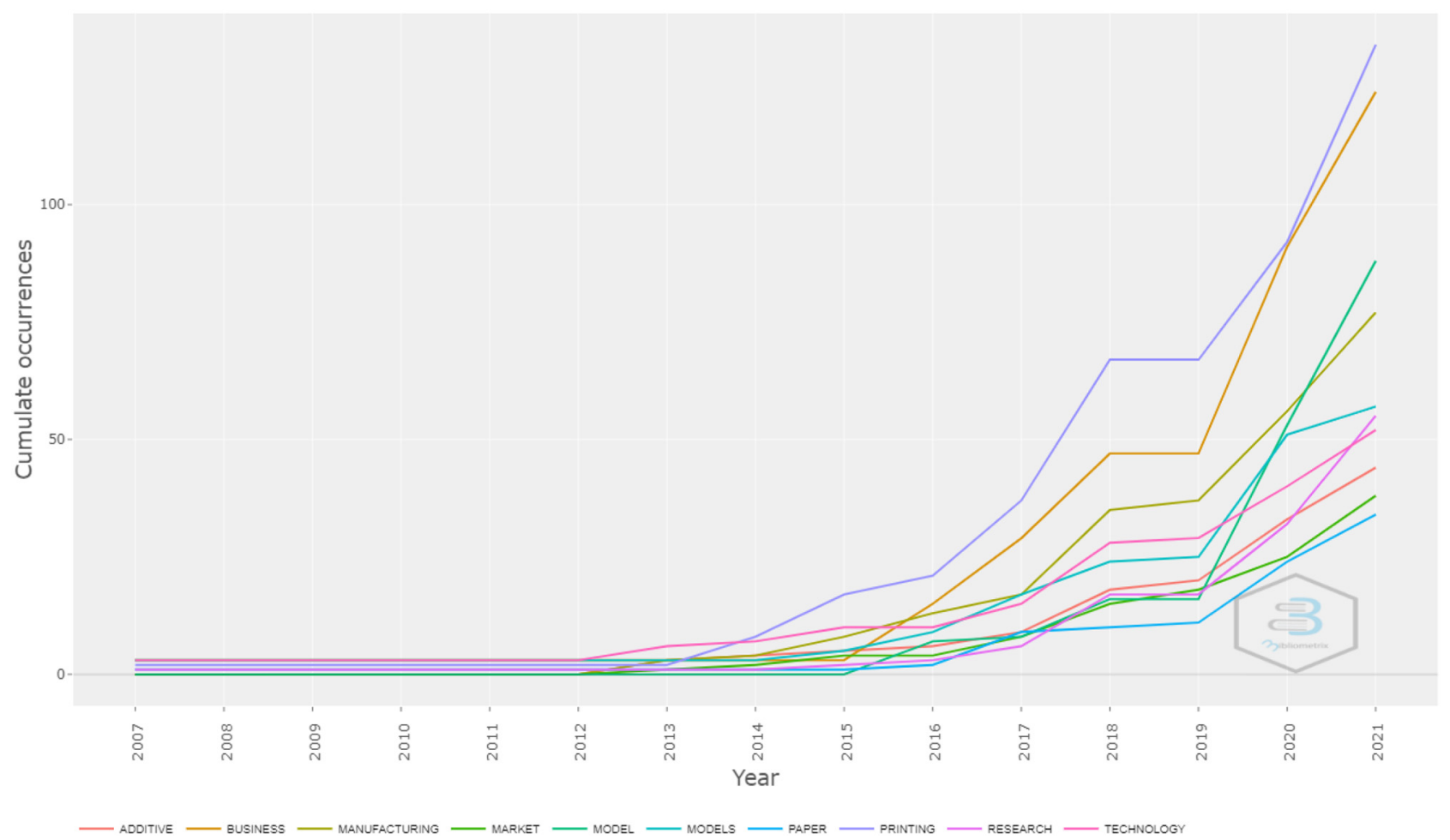

Fig. 9. Word growth.

\subsection{Trends in the number of articles published per year}

Figure 1 depicts the distribution of documents by publication year for papers created and developed during a fourteen-year period [2007-2021]. The overall trend of CAMP-related article publication shows that 2021 was the most active year, with thirteen (13) documents produced, closely followed by twelve (12) articles published in 2020 . However, it is worth mentioning that the 2021 figure are publications done over a nine (9) month period therefore, by the end of the year, the number of publications is expected to increase. CAMP research is attracting a lot of attention. There was however a sharp decline of publications in 2019. This shows that even though cumulatively publications in the area is increasing, research interest is quite unstable. The annual growth rate of publications on CAMP is $32.98 \%$. Figure 2 also represents the number of average citations per year. Whilst citations are increasing, they are not consistent in the growth.

\subsection{Most relevant sources}

The most relevant sources for CAMP publications were also investigated. Figure 3 shows that the top 5 journals combined published $29.62 \%$ of all publications. The journals that published most of the CAMP publications were Technological Forecasting and Social Change, Additive Manufacturing, International Journal of Production Economics, Journal of Manufacturing Technology Management, and Sustainability (Switzerland).
These journals are mostly concerned with themes of technology and business. The sources also emphasise the need for commercialization of technology related products.

\subsection{Source growth}

The contributions of journals to CAMP research depending on the number of publications per year is presented in Figure 4. Each journal is represented by a unique colour code in the line chart. The limit was set to the top five journals because of their unique contributions. It may be noted that the journal which has seen consistent and the highest growth is the technological forecasting and social change journal. It is also clear from the figure that publications in this journal on CAM started in 2016 and the number increased by one each year after 2015. Additive manufacturing journal produced the first paper on CAMP in 2015 and grew until 2019. The rest of the journals have contributed marginally from 2017.

\subsection{Country specific production and collaborations}

Global production of publications in CAMP distribution is shown in Figure 5. The country data (Fig. 5) and collaboration structure (Fig. 6) show that generally, few cross-continent collaborative relations exist. Mainly, collaborations between the United States of America (USA) and the United Kingdom (UK) - Europe. Specific country collaborations are concentrated in Europe, Ireland and 


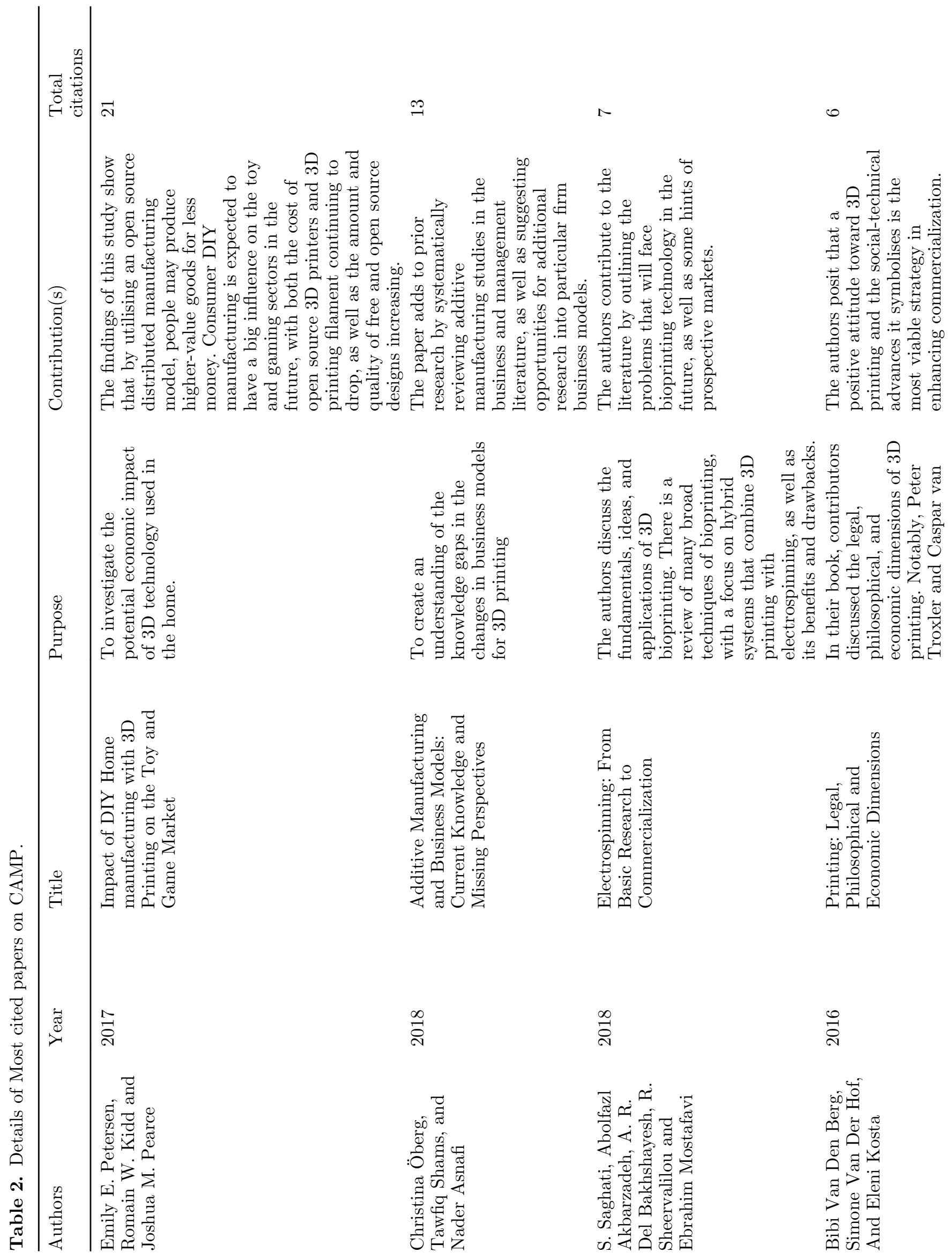




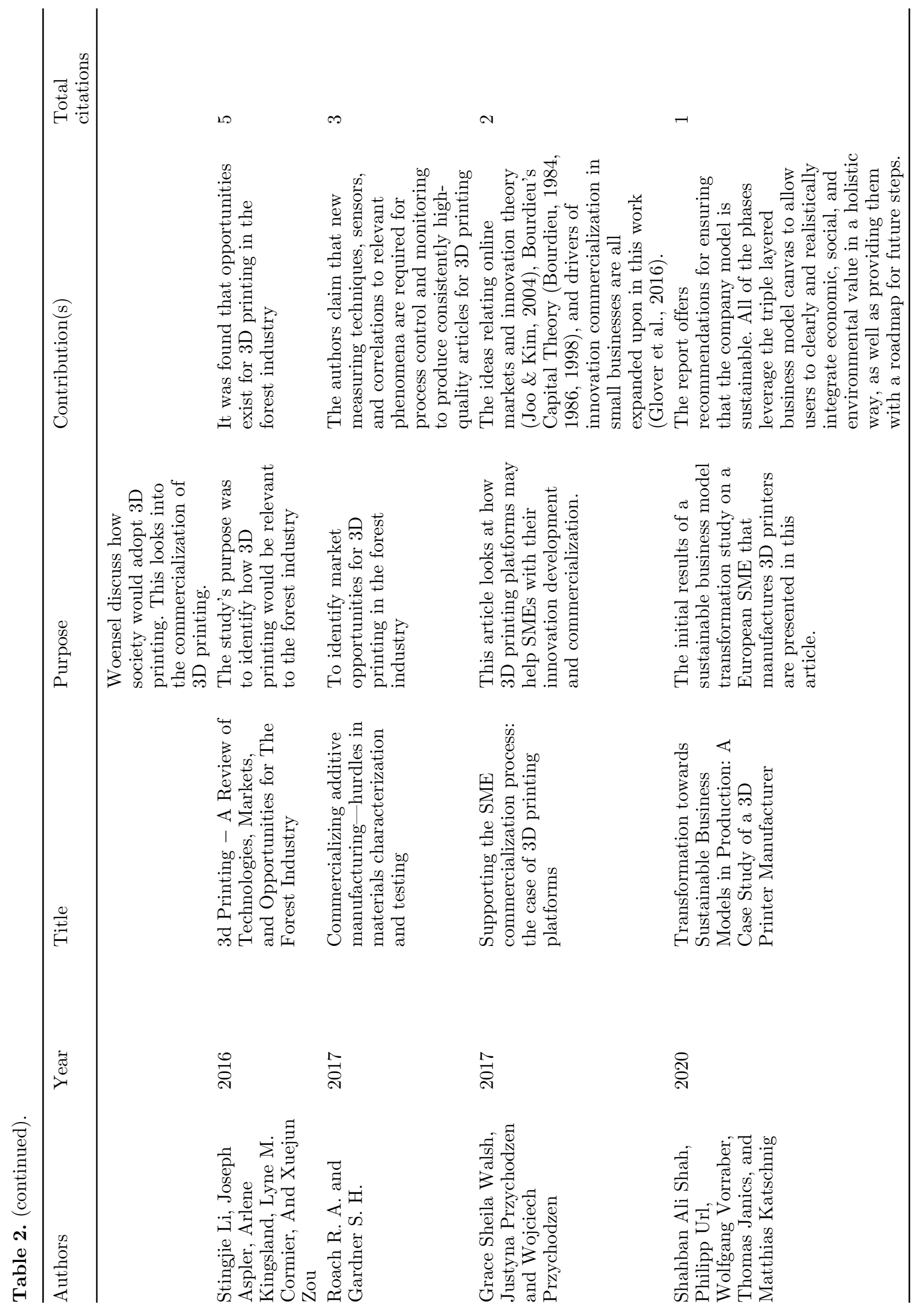



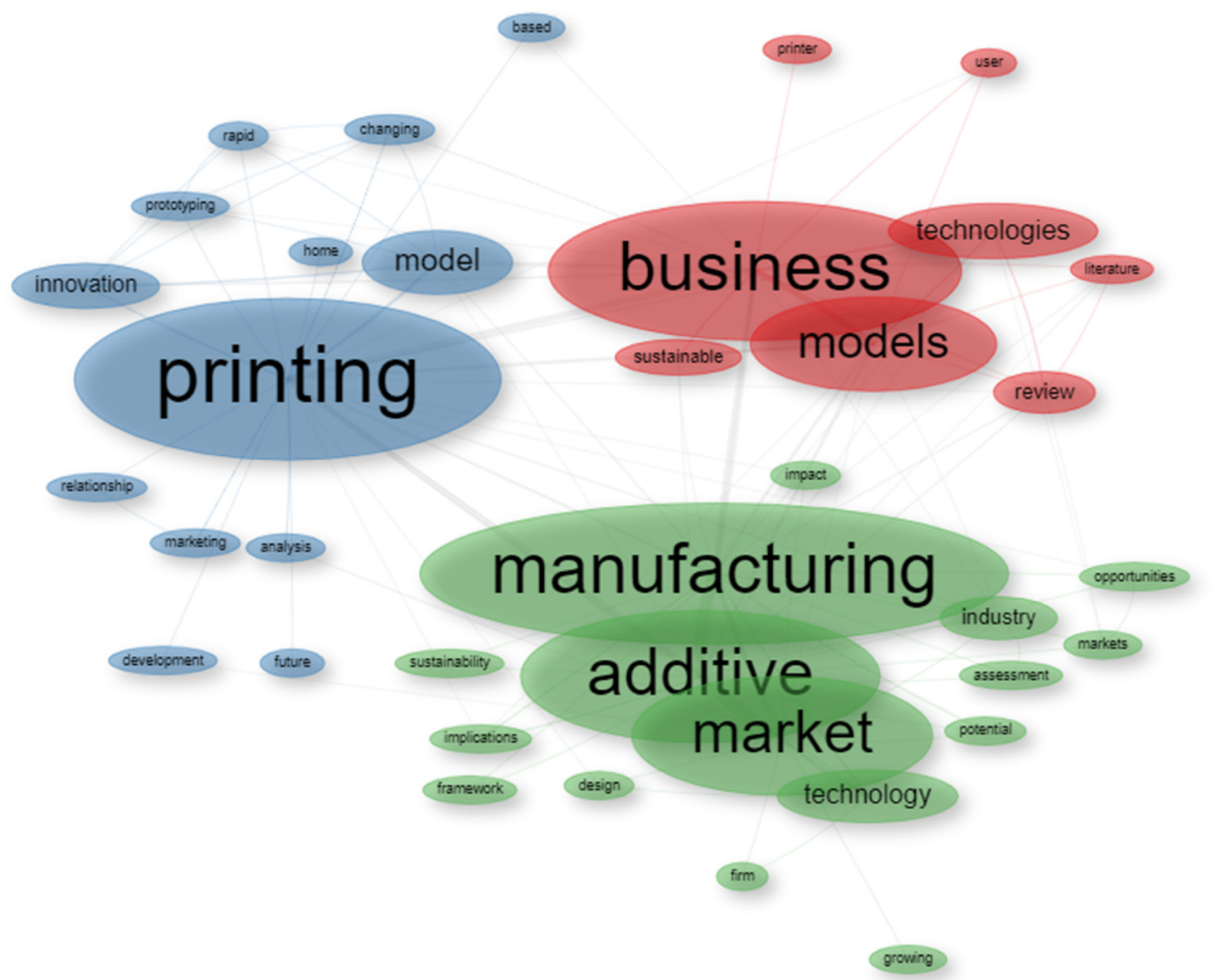

Fig. 10. Keywords co-occurrence network.

Netherlands, Ireland and Spain, Netherlands and Spain, UK and France, UK and Italy, UK and Sweden. Other country collaborations include; USA and Iran, and USA and Sweden. The analysis shows evidence of no collaboration between Africa, Australia, Asia and the rest of the world. The country specific production shows the least production of paper on CAMP from Africa, Australia and Asia. Even though China has produced publications in CAMP, the research is concentrated in the country with less collaborations.

\subsection{Three-field plot of Journals, authors, and abstract keywords}

The three-field plot (Fig. 7) shown below depicts three elements: a list of journal names, authors, and keywords from the abstracts of the articles. Abstracts were used instead of keyword or keyword plus because the abstracts contained much information that would project the key issues in a broader sense. The three elements are connected with grey lines in the figure. The three-field plot shows how the authors are connected to the major keywords in the abstracts and which journal they publish in. The number of papers associated with each element is indicated by the size of each rectangle in each listing category hence the longer the bar, the more prominent that specific issue is in the literature. The journal is the first element on the left. The top journals that published the most papers on the topic of CAMP were the Journal of manufacturing technology management, Journal of technology forecasting and social change, International journal of production economics, Sustainability (Switzerland), Electrospinning, 3D printing, and Automation in construction. The Journal of manufacturing technology management which is depicted by the mauve colour is connected to several authors, namely Holzman P, Breiteecker R, and Schwarz E.

The names of the authors appear in the second element in the middle. Previous elements are linked to authors who published articles in recognised journals, such as Schwarz $\mathrm{E}$, who is linked to two of the journals (Journal of manufacturing technology management and technology forecasting and social change journal) that were linked to the keywords and sources. However, some others, such as Addo Tenkorang R, Anderson P and Na N, did not publish in indexed journals and thus have no affiliation with any of the journals listed. On the right, each of the authors is linked to a list of frequently used keywords in the abstracts. This plot includes a list of the top fourteen (14) authors. The size of the rectangle indicates how many papers each author has written. Holzman P, Breiteecker R, and 


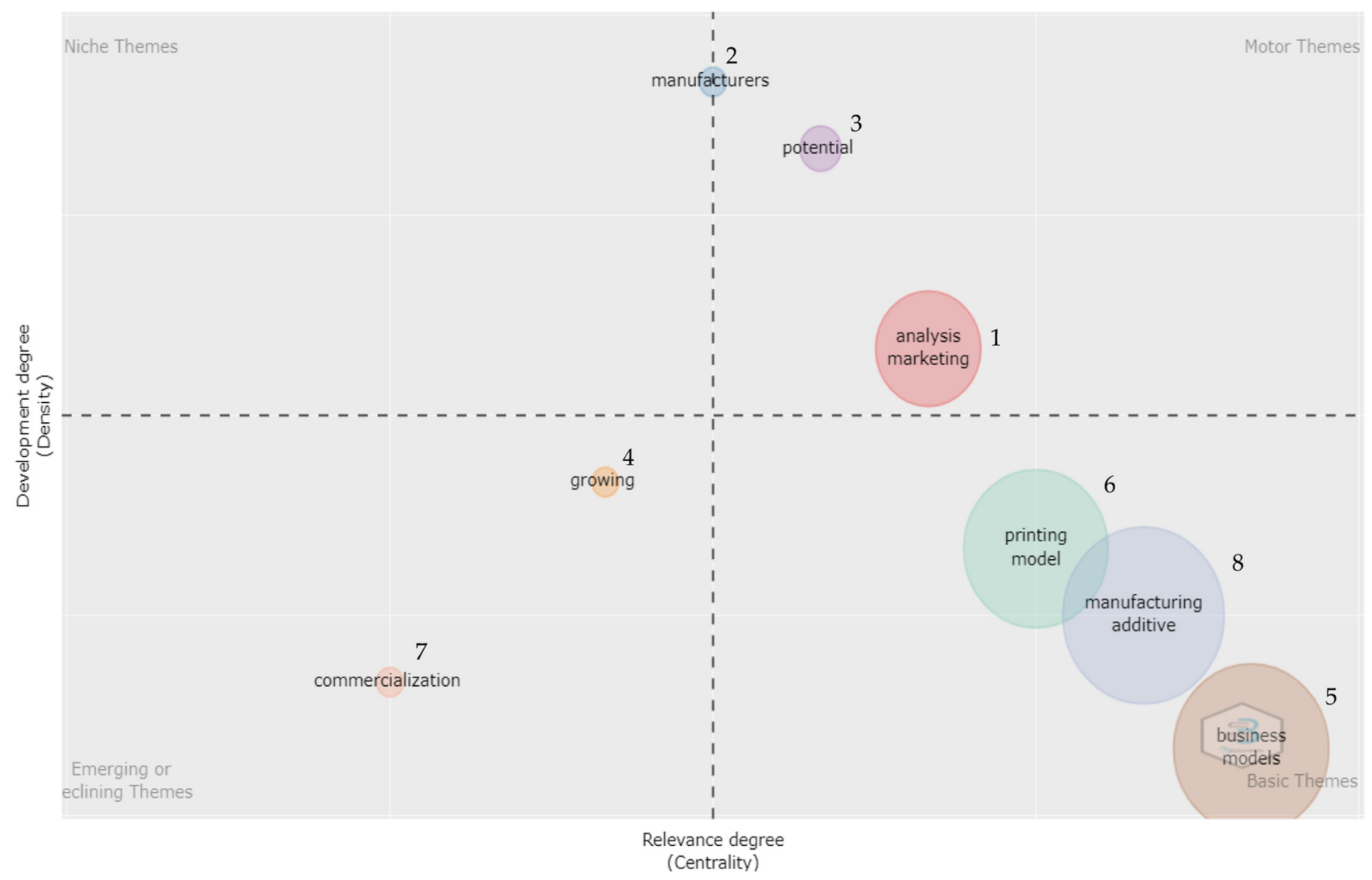

Fig. 11. Thematic map.

Schwarz E had the largest rectangles in this plot (of equal size) followed by Ribeiro I and Altparmak S. These were the top 5 most published authors.

The third element contains the most frequently used keywords in the abstracts of papers. Each keyword is linked to authors who have written extensively on the subject. Fifteen (15) keyword topics are listed, with "Business" appearing the most frequently, as evidenced by the size of the light green rectangle, which dominated the other rectangles. It also appeared that almost all the registered authors used either manufacturing or business-related topics, which is consistent with the focus of this study on scientific papers related to CAMP. This graph also shows several other commonly used keywords, such as "model(s)", which mostly relate to business model(s) and "printing," which also relates to 3 -dimensional printing. Other prominent words include 'technology', 'manufacturing', 'research', 'industry and market'.

\subsection{Most cited papers in CAMP}

Table 2 presents a detail of the most cited papers on CAMP. The most cited paper was authored by Petersen et al. [38]. The paper has been cited 21 times in refereed journals. The number of citations per paper is relatively low for an important area of research like this. This demonstrates that the CAMP research is quite young and requires more attention. The total citations cumulatively are 58. There remain several unexplored areas that require much attention. The most cited paper by Petersen et al. [38], is focused on the potential economic impact of 3D technology. Based on an understanding of the commercial impact of additive manufactured products, a case for the commercialization of such products is made evident. The paper focuses on the economic value of $3 \mathrm{D}$ printed products to the consumer. Whereas most papers lament the financial intensity of 3D production. This paper, therefore, sets the pace for a shift to analysing consumer benefits.

\subsection{Word cloud and word growth}

Figure 8 shows a visual representation of the words that featured most frequently in the articles on the subject of CAMP. To take a longitudinal look at the growth of keywords in CAMP research, the word cloud analysis was examined from two time periods, 2007-2019 and 20202021. A critical look at Figure 1 which shows the global production of papers on CAMP reveals a renewed and sustained interest in the area after 2019. The evidence shows that papers published after 2019 contribute $46.3 \%$ to the total publications. Hence it was considered important to examine the two time periods. The magnitude of the words in the word cloud is determined by how many times they appear. The word placement is random, but the most important words are in the middle to make them more noticeable due to their enormous size. 


\section{Conceptual Structure Map - method: MCA}

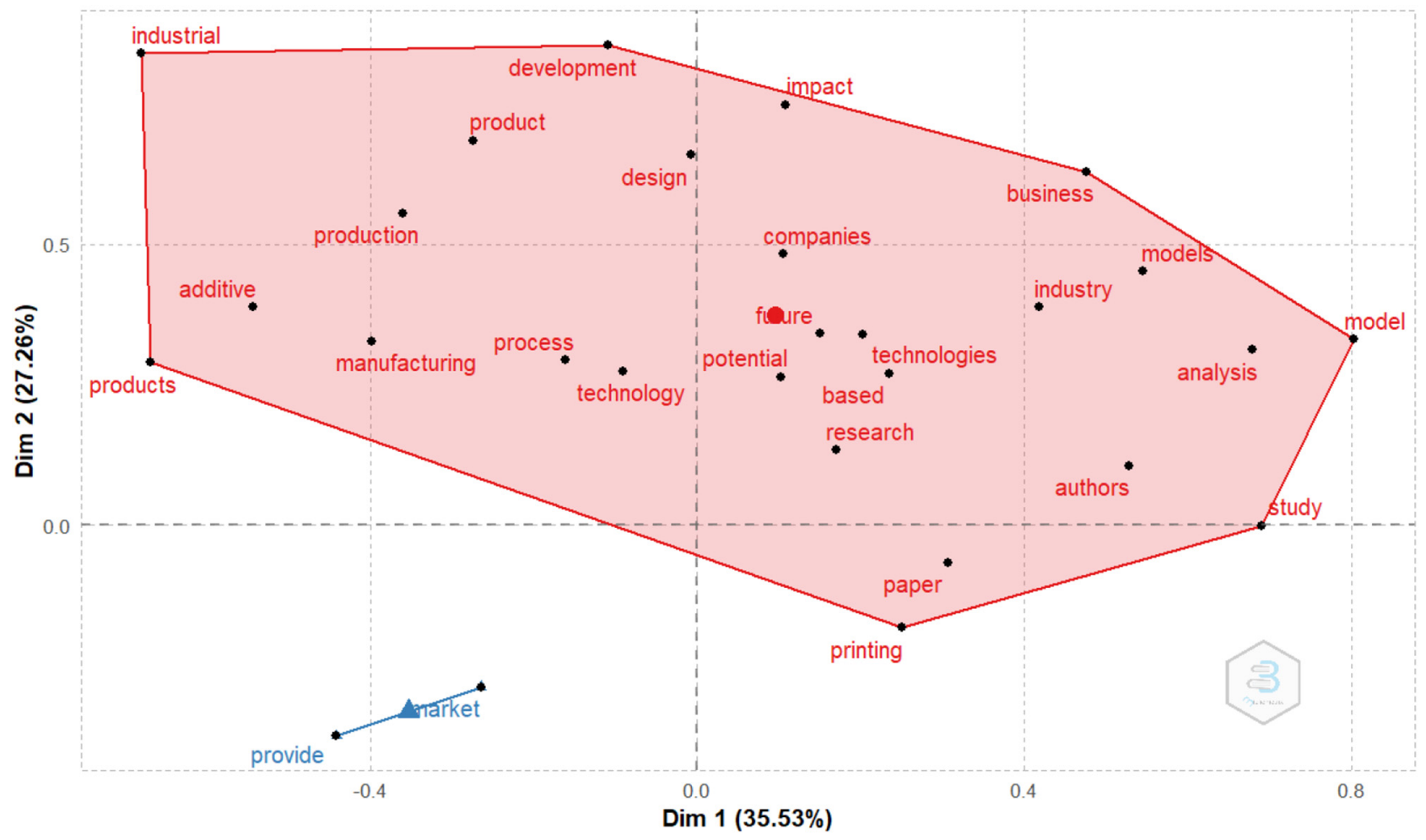

Fig. 12. Conceptual structure map.

\section{Topic Dendrogram}

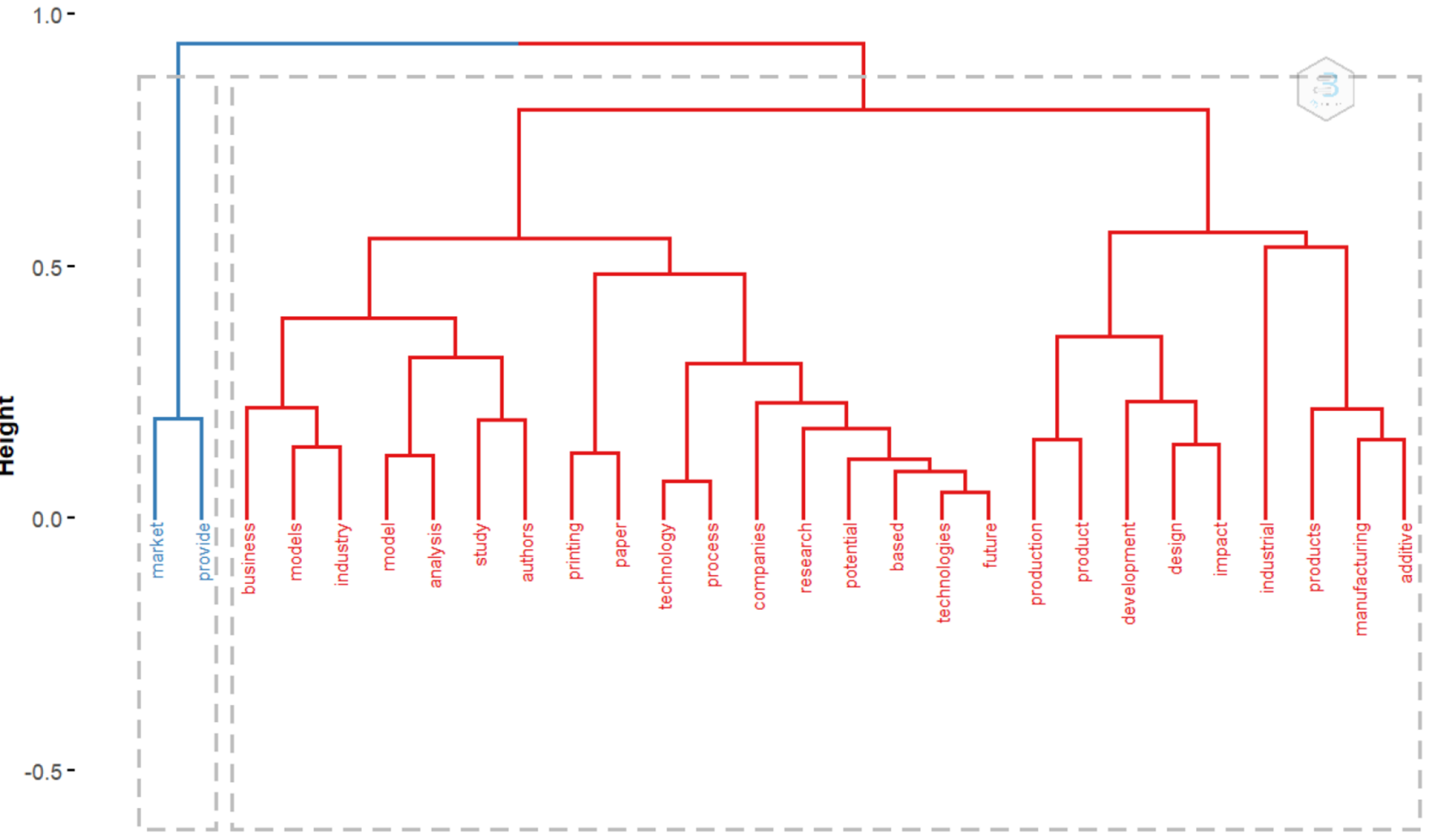

Fig. 13. Topic dendrogram. 


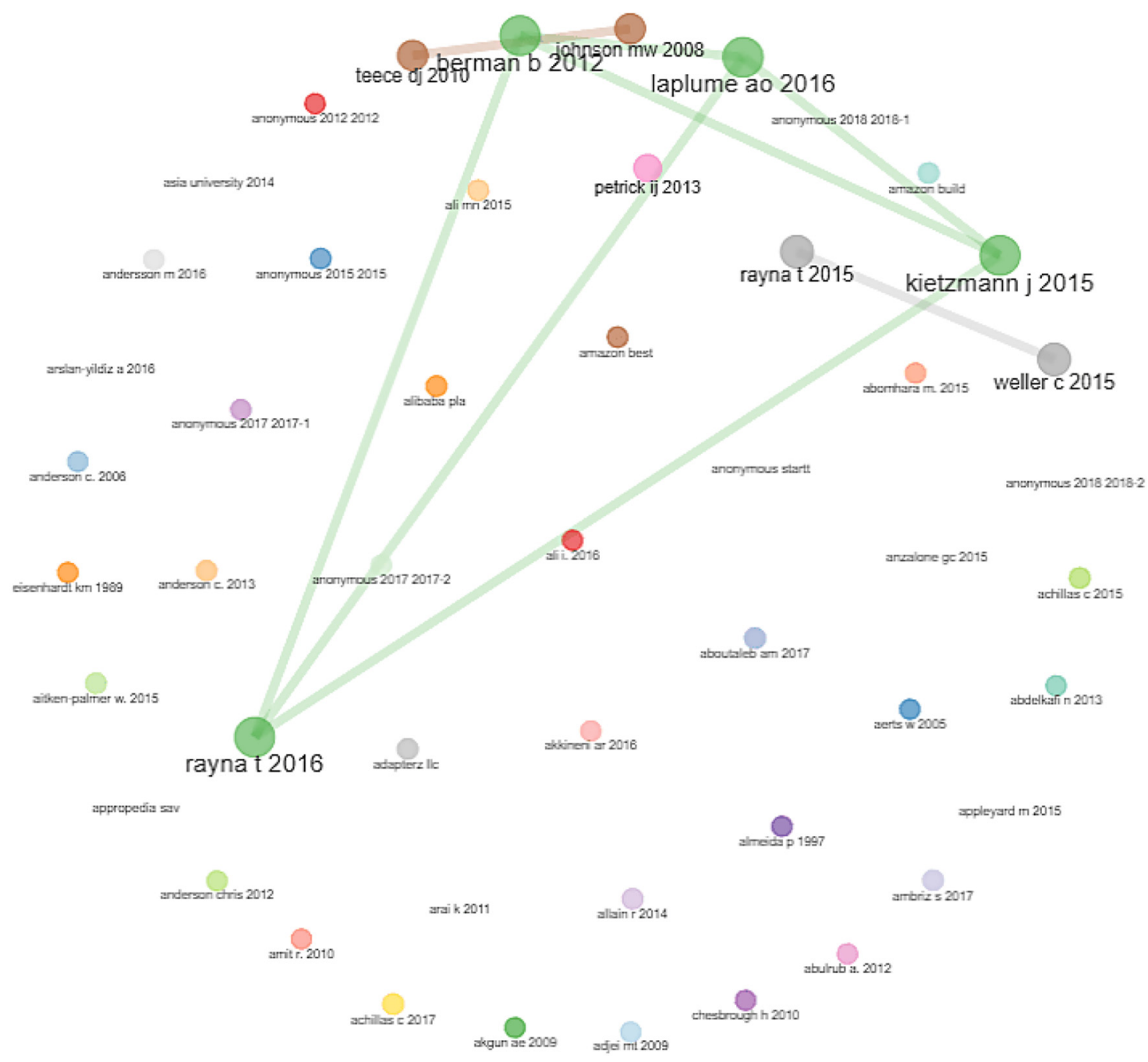

Fig. 14. Intellectual structure (co-citation network).

Studies on CAMP have consistently focused on "Printing" and "business" which are similar words in the word cloud in the two time periods. The two time periods, however, diverge in that the second set of years places a greater emphasis on model (business model). A closer examination of the word clouds reveals that the term "business" appears more frequently in recent publications than in previous publications. This supports the findings of the thematic map (Fig. 11) as one of the clusters being studied by scholars. In recent research, the term business model has gained significance, implying that more emphasis is being devoted to the ways to enhance the commercialization of additive manufactured products. Which attest to the fact that the pioneers of the CAMP research focus on the engineering dimensions of AM to enhance the production efficiency, optimum process parameters, CAD models, mechanical properties etc., without paying much attention to the business (commercialisation) dimension of the CAMP research [23]. This negligence might have also contributed to the low adoption of AM technology despite its enormous competitive advantage over the conventional methods of manufacturing $[36,39]$.

\subsection{Word growth}

Word growth assessment offers insight into the usage of keywords in the literature which enhances the understanding of how new terms evolve in the literature. Figure 9 describes the major keywords in the CAMP literature and provides an understanding of the periods they were introduced into the literature and possibly, their effect on the dynamics of the literature. The oldest keywords are Printing, Business Models, and technology. The word 'market' was introduced into the literature in 2013 and 'model' in 2016.

\subsection{Keywords co-occurrence network}

In addition, the keywords co-occurrence network (KCN) was investigated in order to gain a better understanding of the trends in the field of CAMP. The KCN analysis shows how keywords in literature are linked, providing insight into the field's knowledge structure [40]. As a result, the findings show that, in addition to identifying common keywords (as shown in Fig. 8), KCN also revealed connections between them (see Fig. 10). Some keywords 
appear to have a greater impact on a network. A close examination of these keywords based on their colour codes, for example, suggests that a larger keyword represented by their sizes is cohesively connected to smaller keywords. Business, for example, is linked to models, technologies, sustainable and printer.

\subsection{Thematic map}

A thematic map based on density and centrality was also developed, which was separated into four topological zones (Fig. 11). This result was produced using a semi-automated method that examined the titles of all the references included in this study, as well as extra relevant keywords (other than the author's keywords) to capture deeper variations. The thematic analysis revealed eight (8) significant clusters: analysis, manufacturers, potential, growing, business, printing, commercialization, and manufacturing. These eight clusters organise the articles in a logical manner. Common terms were recorded for each cluster.

Analysis, and marketing are among the keywords in the first cluster (analysis). The second cluster was made up of one keyword, 'manufacturers'. The third cluster also consisted of one keyword which is 'potential'. Similarly, the fourth cluster had one keyword which is 'growing'. The fifth cluster consisted of keywords such as 'business', 'models'. The sixth cluster also consisted of 'printing', 'model'. The seventh cluster had one keyword, 'commercialization' Finally, the eight-cluster consisted of 'manufacturing', 'additive'.

The thematic map shows the main themes emerging from the literature. Themes in the upper right quadrant (analysis, marketing and potential) are well-developed, important for the organisation of the research field, and externally related to concepts applicable to other themes. These themes are known as motor or driving themes. They have high density and centrality and are described as very important for future research [41]. Hence, themes such as analysis, marketing and potential should be given much focus in future studies since they are likely to drive future research in the field of CAMP.

Specialized themes in the upper left quadrant maintain well-developed internal but not external relationships. Themes in this quadrant are known as niche themes. They are under-represented topics but are areas of rapid development as they are indicated by high centrality but low density [42]. The theme 'manufactures' lies in the border of the two quadrants on the top. Manufacturers as a theme may thence be described as having high centrality and moderate density. This theme is central to the research area but requires more focus. This seems to mean that the theme must be looked at in a different light.

Because of their low density and centrality in the network, themes in the lower left quadrant ('commercialization' and 'growing') are considered developing or declining [43]. They have not received much attention in the literature and therefore must be looked at.
Themes in the lower right quadrant group are basic, general, and transversal themes [41]. They are indicated by high density but low centrality. Major themes in this quadrant are 'printing', 'manufacturing', and 'business'. The number of documents corresponding to each keyword in a theme is proportional to the size of the sphere associated with that theme. The name of the most important word associated with the theme is used to label each thematic network (usually identified as the most central word in the theme).

There is a greater need for a specific concentration on commercialization because it falls in the quadrant of emerging themes. The position of the theme 'commercialization' on the thematic map clearly confirmed that research on commercialisation of AM products might have been neglected and only now that research interest on commercialisation of AM products begins to develop. However, it may be seen that 'business model' which is a synonymous concept lies in the domain of basic themes. This suggests that commercialization is both an emerging and basic concept that is central to the studies on additive manufacturing. That notwithstanding, marketing which is a major concept in commercialization is identified by the thematic map as a motor theme which is very important in CAMP.

\subsection{Conceptual map and topic dendrogram}

A conceptual structure map was generated, encompassing a visualization of the contextual structure of each word that appeared often in the articles on CAMP by mapping the relationship between one word and another through regional mapping (Fig. 12) also shown in the topic dendrogram (Fig. 13). Each word is placed based on the values of Dim 1 and Dim 2, Dim being a specific term in bibliometric science, resulting in mapping between words whose values did not differ significantly.

This map is divided into two sections: a red area and a blue area, both of which contain words that are related to one another. The red area, which contained the top five (5) words that appeared most frequently ('business', 'manufacturing', 'model', 'additive' and 'printing') (see Figs. 9 and 10), contained a large number and variety of words, indicating that many research papers presented connections between the words listed in this region, which contained the top five words that appeared most frequently. The blue network represents a different cluster. This cluster contains two connected words 'market' and 'provide'. The market represents a customer focus. This suggests that a new niche of concentration of research in the area is on the market.

Analysing the two clusters, a distinction is drawn between a focus on the firm and a focus on the market. The larger cluster examines the business models that are appropriate for additive manufacturing (AM) and how AM firms can ensure that they are profitable whereas the smaller cluster focuses perhaps on the adoption of AM products by the consumers. This confirms the findings from the thematic map which shows that commercialisation is an emerging theme. 


\subsection{Intellectual structure (co-citation network)}

Document co-citation analysis (DCA) is a type of computational analysis that is based on the frequency of citations [29]. The DCA is widely used to evaluate the network or degree of links between texts based on citations that they share [29]. According to Ramos-Rodrguez and Ruz-Navarro [44], periodical publications with peer review have demonstrated their validity after a thorough evaluation, affirming the significance of document co-citation. Small [29] developed document co-citation analysis as a measure of the degree of relationship between articles as evaluated by the citing authors. Each document expresses its own notions, methodologies, or concepts that are generally found in the citing documents, according to Small and Griffith [45]. As a result, these co-citation analyses are presented as a "field's view" representation. A document co-citation pair occurs when two papers are jointly cited in the same citing document [29]. As a result, the more co-citations two documents acquire, the stronger their co-citation strength is and the more probable they are bibliographically related. In other words, it is thought that these two cited publications are more comparable than others.

Using document co-citations to analyse the intellectual structure of various scientific disciplines has been demonstrated to be a valid strategy in numerous research [46,47]. In recent years, related co-citation analysis has become more widely used in research [47,48]. To summarise, document cocitation analysis is a helpful method for determining the intellectual structure of papers from the same discipline in the CAMP literature. It is also important to use document co-citation analysis to understand how CAMP studies relate to one another and to express the CAMP field's perspective.

Figure 14 shows the co-citation network of publications on CAMP. There are 41 isolated nodes indicating publications that have not been co-cited in the CAMP research. The connected nodes are seen at the upper right of the circle (Fig. 14). The lines connect the nodes to form a cluster of co-cited references. There are three identified clusters. The most prominent cluster (cluster 1) is seen with green lines connecting the nodes. The next cluster (cluster 2) are nodes linked with a brown line and the last cluster (cluster 3 ) are two publications linked with an ash line. Table 3 shows the details of the articles that form the clusters.

\section{Discussions}

Using bibliometric analysis, this study attempted to provide a comprehensive review of scientific publications in the field of CAMP over time. The study looked into the themes of CAMP in publications, recognized influential scholars and their contributions, looked into social networks and collaborations across institutions, countries, and regions over time, and presented a thematic analysis of the field of CAMP, including its current state and future prospects.

\subsection{Demographics}

This work contributes to the body of knowledge in several ways. First, the study discovered that the first paper on
CAMP was published in 2007 but the actual growth of publications started in 2012, indicating that the field of CAMP is still young. This research identified relevant publishing outlets. "Technological forecasting and social change" is the most prominent of the study's publishing sources. This finding is useful for scholars in determining which publishing outlet is best for their research papers and the focus of CAMP research. Furthermore, a review of relevant articles found that Petersen et al. [38]'s work stands out; these authors' work primarily focused on the impact of Do-It-Yourself (DIY) Home Manufacturing with 3D Printing on the Toy and Game Market. Their work may pave the way for future discussions about the features and characteristics of CAMP from a technological, market and pedagogical standpoint. Similarly, the findings show that the United States has produced the most scientific works in the field of CAMP over time. As a result, the United States appears to have remained the most relevant country in the field of CAMP.

\subsection{Growth of CAMP research}

Furthermore, the study found that the field of CAMP is rapidly evolving, with terms like "Business", "marketing", "printing", and "model" emerging and growing. The results of the thematic analysis show that new themes like 'commercialization' are emerging and are linked to CAMP. The study also revealed that "additives" will continue to be the most popular topic in 2021. These findings highlight the importance of conducting more research in the market for AM products. From the analysis, it recommended that research units establish more extensive research collaborations between scholars and institutions, which will result in a greater global impact on the potential of CAMP to improve learning outcomes.

\subsection{Major focus areas from the intellectual structure}

The document co-citation (intellectual structure) reveals three major historical areas where CAMP research has been concentrated. The co-citation network displays the most frequently cited sources in recent studies. The first cluster examines how AM has transformed businesses, the second examines business models that prepare AM firms for commercialization, and the third examines co-creation and the economic impact of AM. Clearly, the three clusters have focused on business evolution, business operations, and customers, in that order.

AM has transformed businesses by allowing companies to produce unique variants of products at a lower cost, as well as prototypes and critical products like dental crowns, artificial limbs, and bridge manufacturing [49]. The papers that rely on citations from the first cluster emphasise the importance of $\mathrm{AM}$ in its application. In addition, this cluster contains citations to works on AM's disruptive competencies and their applications. This disruption has impacted entire value chains, resulting in new business models [50].

In terms of business models, the majority of publications relied on publications by Teece [51] and Johnson [52]. These articles are about how to change business models and 
Table 3. Clusters of intellectual structure.

\begin{tabular}{lll}
\hline Node & Cluster & Title of Node (article) \\
\hline Berman, B. (2012) & 1 & $\begin{array}{l}\text { 3-D printing: The new industrial } \\
\text { revolution }\end{array}$
\end{tabular}

Main contribution

This article examines the characteristics and applications of 3-D printing, as well as how it compares to other manufacturing processes such as mass customization and other forms of customization. Using the argument that 3-D printing allows to produce small quantities of customised goods at a relatively low cost. Even though it is currently used primarily for the production of prototypes and mock-ups, there are a number of promising applications in the production of replacement parts, dental crowns, artificial limbs, and bridge manufacturing.

Kietzmann, J., $1 \quad$ Disruptions, decisions, and Pitt, L., \& Berthon, P. (2015)

Laplume, A. O., Petersen, B., \& Pearce, J. M. (2016)

Rayna, T., \& (2016)

Johnson, M. W., Christensen, C. M., \& Kagermann, H. (2008)

Teece, D. J. (2010) 2 destinations: Enter the age of 3 -D printing and additive manufacturing

Global value chains from a 3D printing perspective

From rapid prototyping to home fabrication: How $3 \mathrm{D}$ printing is changing business model innovation

Reinventing Your Business Model

Business Models, Business Strategy and Innovation
The authors provided an overview of the fundamentals of 3-D printing for managers, as well as some of the decisions that they will need to make. The paper discusses the potential disruptions that technology may cause, as well as the implications of these disruptions for businesses and consumers. Aside from that, the authors brought attention to the legal and ethical issues that the technology will present to policymakers in the future. While the authors have begun to speculate about the possible directions that 3-D printing technology will take in the future, astute managers in almost every industry will want to keep a closer eye on the technology as it continues to develop and evolve. The authors raise concerns about the impact of open-source additive manufacturing technologies on GVC configuration in the future. Suggestion that the adoption of 3D printing technology in a particular industry is linked to a shift toward shorter, more scattered global value chains. As a result, in some industries, new manufacturing technology is expected to push manufacturing value chains closer to end-users and more localised.

This article demonstrates how 3D printing technologies have the potential to revolutionise business model innovation by enabling adaptable business models and applying the 'rapid prototyping' concept to the process.

The authors discuss how firms can successfully change their business models

The author investigates the importance of business models in relation to company strategy, innovation management, and economic theory. 
Table 3. (continued).

\begin{tabular}{|c|c|c|c|}
\hline Node & Cluster & Title of Node (article) & Main contribution \\
\hline
\end{tabular}

the value of business models. Because of the uniqueness of AM companies' processes, the publications that rely on these citations claim that new business models are required. Furthermore, Montes et al. [53] argue that AM may have an impact on the creation of entirely new businesses and business models.

Finally, the focus of some of the publications has been on customer participation in the innovation process [54]. This is, in fact, the most recent viewpoint on CAMP. The importance of customer value in the development of AM products leads to the creation of more personalized and unique outputs. Aside from that, the majority of recent CAMP publications have focused on the benefits that customers would receive, such as lower prices [55].

\subsection{Limitations and avenues for future studies}

Whilst the study has been robustly undertaken, just as all other studies, it is plagued with some limitations. First, even though a large net of keywords were used, there may be other related issues that have not been addressed. Secondly, the databases used were Scopus and web of science which provided a broader scope of studies. That notwithstanding, there are studies that are outside these databases that might provide other relevant information to the study. It is possible that some studies might have been overlooked by the two databases. Thirdly, the impact factor of the journals in which the articles were published was not used as a filter for the papers in the analysis.
Because the peer-review process varies amongst publications, this might prompt readers to doubt whether it is acceptable to interpret the conclusions of some articles. However, as seen in Figure 3 (most relevant sources), journals that publish CAMP studies are frequently regarded as top tier journals. Future studies may contribute by expanding the keywords used and the databases as well.

Beyond these limitations of this study, there are several opportunities for scholars to advance the CAMP literature. The study provides emerging areas that require attention. Up to this point, scholars have focused mainly on business models and internal business operations that increases the propensity for the commercialisation of additive manufactured products. An emerging area from the analysis in this study is the 'market', suggesting that scholars should consider the needs of the market. By focusing on the needs of the market, scholars can better investigate which areas of AM must be focused upon. For instance, there is a growing demand for AM products by hospitals and the aerospace industries. In this case, hospitals and the aviation industry may be considered as the market for AM products.

It also came to light that, researchers need to devote more time and effort to the consumer side of the commercialization of AM products, as this is the future research topic in CAMP research, according to the findings. Since the studies from Africa, Asia and Australia are scant, there should be more studies from those geographic areas to broaden the 
understanding of CAMPs. Also, more collaborative studies should be conducted between Africa, Australia, Asia, and the rest of the world.

\section{Conclusions}

This study examined all studies on the commercialization of additive manufactured products archived by Scopus and web of science. To summarize, the findings of this study will help researchers, particularly young scholars in CAMP, better understand the research landscape and future research hotspots. Young researchers just starting out in the field of CAMP, can quickly identify top articles, prolific authors, and research hotspots. Furthermore, the research identifies emerging topics in the field of CAMP that needs to be further developed. The findings of this study provide a quick overview of the output in this field over the years, as well as a useful pointer to the field's future direction. Importantly, the study shows a shift to more consumerfocused research. It is worth noting that the number of article collections studied came exclusively from the two databases (Scopus and web of science) and were articles published before $4^{\text {th }}$ October 2021, hence, future changes and developments are still possible.

\section{Conflicts of Interest}

The authors declare no conflict of interest.

Acknowledgement. This research was funded by the Collaborative Program in Additive Manufacturing (Contract No CSIRNLC-CPAM-18-MOA-CUT-01).

\section{References}

1. S.N. Economidou, D.A. Lamprou, D. Douroumis, 3D printing applications for transdermal drug delivery, Int. J. Pharm. 544 (2018) 415-424

2. T.C. Dzogbewu, W.B. du Preez, Additive manufacturing of Ti-based intermetallic alloys: a review and conceptualization of a next-generation machine, Materials 14 (2021) 4317

3. T.C. Dzogbewu, Additive manufacturing of TiAl-based alloys, Manuf. Rev. 7 (2020) 35

4. D.V. Mahindru, Review of rapid prototyping-technology for the future, Global J. Comput. Sci. Technol. Available online: http://computerresearch.org/index.php/computer/article/ view/410 (accessed on 2 September 2021)

5. T.C. Dzogbewu, Laser powder bed fusion of Ti15Mo, Results Eng. 7 (2020) 100155

6. T. Dzogbewu, Additive manufacturing of porous Ti-based alloys for biomedical applications - a review, J. New Gener. Sci. 15 (2017) 278-294

7. T.C. Dzogbewu, Laser powder bed fusion of Ti6Al4V lattice structures and their applications, J. Met. Mater. Miner. 30 (2020) 68-78

8. T.L. Gerstle, A.M.S. Ibrahim, P.S. Kim, B.T. Lee, S.J. Lin, A plastic surgery application in evolution: three-dimensional printing, Plast. Reconstr. Surg. 133 (2014) 446-451
9. T. Wohlers, Wohlers Report 2016. 3D printing and additive manufacturing state of the industry, Wohlers Rep. 2016 (2016) 355

10. L. Wood, Global metal 3D Printing Market Analysis Report 2021-2028 - Untapped End-Use Industry Verticals and Markets Such as Printed Electronics and 3D-Printing Under Water - ResearchAndMarkets.Com | Business Wire Available online: https://www.businesswire.com/news/home/ 20210818005298/en/Global-Metal-3D-Printing-MarketAnalysis-Report-2021-2028-Untapped-End-use-IndustryVerticals-and-Markets-Such-as-Printed-Electronics-and3D-Printing-Under-Water-ResearchAndMarkets.com (accessed on 28 October 2021)

11. N. Shahrubudin, T.C. Lee, R. Ramlan, An overview on 3D printing technology: technological, materials, and applications, Proc. Proc. Manufactur. 35 (2019) 1286-1296

12. ASTM ASTM F2792 - 12a Standard Terminology for Additive Manufacturing Technologies, (Withdrawn 2015) Available online: https://www.astm.org/Standards/F2792. htm (accessed on 2 September 2021)

13. H. Bikas, P. Stavropoulos, G. Chryssolouris, Additive manufacturing methods and modelling approaches: a critical review, Int. J. Adv. Manuf. Technol. 831 (2015) 389-405.

14. I. Gibson, D. Rosen, B. Stucker, Directed energy deposition processes, Addit. Manuf. Technol. (2015) 245-268

15. I. Gibson, D. Rosen, B. Stucker, Sheet lamination processes, in Additive Manufacturing Technologies (Springer, New York, 2015), pp. 219-244

16. R. Singh, A. Gupta, O. Tripathi, S. Srivastava, B. Singh, A. Awasthi, S.K. Rajput, P. Sonia, P. Singhal, K.K. Saxena, Powder bed fusion process in additive manufacturing: an overview, Proc. Mater. Today 26 (2019) 3058-3070

17. Y.Y.C. Choong, H.W. Tan, D.C. Patel, W.T.N. Choong, C.H. Chen, H.Y. Low, M.J. Tan, C.D. Patel, C.K. Chua, The global rise of 3D printing during the COVID-19 pandemic, Nat. Rev. Mater. 5 (2020) 637-639

18. R. Arora, P.K. Arora, H. Kumar, M. Pant, Additive manufacturing enabled supply chain in combating Covid-19, J. Ind. Integr. Manag. 5 (2020) 495-505

19. T.C. Dzogbewu, L. Monaheng, I. Yadroitsava, W.B. Du Preez, I. Yadroitsev, Finite Element Analysis in Design of DMLS Mandible Implants, CRC Press/Balkema, 2017, pp. 155-160

20. S. Choi, H. Cheung, Digital fabrication of multi-material objects for biomedical applications, in Biomedical Engineering, Trends in Materials Science (2011)

21. T.G. Spears, S.A. Gold, In-process sensing in selective laser melting (SLM) additive manufacturing, Integr. Mater. Manuf. Innov. 5 (2016) 16-40

22. T.C. Dzogbewu, W.B. du Preez, Additive manufacturing of titanium-based implants with metal-based antimicrobial agents, Metals 11 (2021) 1-12

23. G. Liu, K. Rong, The nature of the co-evolutionary process: complex product development in the mobile computing industry's business ecosystem, Group Organ. Manag. 40 (2015) 809-842

24. E.E. Petersen, R.W. Kidd, J.M. Pearce, Impact of DIY home manufacturing with $3 \mathrm{D}$ printing on the toy and game market, Technologies 5 (2017). doi:10.3390/technologies5030045

25. J. West, G. Kuk, The complementarity of openness: how makerbot leveraged thingiverse in $3 \mathrm{D}$ printing, Technol. Forecast. Soc. Change 102 (2016) 169-181 
26. A. Pritchard, Statistical bibliography or bibliometrics, J. Doc. 25 (1969) 348-349

27. D.L. Hoffman, M.B. Holbrook, The intellectual structure of consumer research: a bibliometric study of author cocitations in the first 15 years of the journal of consumer research, J. Consum. Res. 19 (1993) 505

28. F.F. Charvet, M.C. Cooper, J.T. Gardner, The intellectual structure of supply chain management: a bibliometric approach, J. Bus. Logist. 29 (2008) 47-73

29. H. Small, Co-citation in the scientific literature: a new measure of the relationship between two documents, J. Am. Soc. Inf. Sci. 24 (1973) 265-269

30. M. Bartolini, E. Bottani, E.H. Grosse, Green warehousing: systematic literature review and bibliometric analysis, J. Clean. Prod. 226 (2019) 242-258

31. M. Zhang, S. Guo, C. Bai, W. Wang, Study on the impact of haze pollution on resident's green consumption behavior: the case of Shandong province, J. Clean. Prod. 219 (2019) 11-19

32. J. Zhu, W. Liu, A tale of two databases: the use of web of science and scopus in academic papers, Scientometrics (2020) 1-15

33. C. Analytics, Web of Science. Trust Differ. Web Sci. Fact Book Available Online Httpimages Info Sci. Thomsonreuters BizWebThomsonReutersScience 7Bd6brfaae-3cc2-41868985-A6ecc8cce1ee 7DCrvWoSUpsellFactbookA4FALRedits Pdf (accessed 10 October 2017)

34. Elsevier About Scopus - Abstract and Citation Database | Elsevier Available online: https://www.elsevier.com/solu tions/scopus (accessed on 11 October 2021)

35. H. Aveyard, Doing a Literature Review in Health and Social Care: A Practical Guide (2018)

36. E. Aromataris, D. Riitano, Constructing a search strategy and searching for evidence, Am. J. Nurs. 114 (2014) 49-56

37. M. Aria, C. Cuccurullo, Bibliometrix: an R-tool for comprehensive science mapping analysis, J. Informetr. 11 (2017) 959-975

38. E.E. Petersen, R.W. Kidd, J.M. Pearce, Impact of DIY home manufacturing with $3 \mathrm{D}$ printing on the toy and game market, Technologies 5 (2017)

39. A. Vafadar, F. Guzzomi, A. Rassau, K. Hayward, Advances in Metal Additive Manufacturing: A Review of Common Processes, Industrial Applications, and Current Challenges; MDPI AG (2021) Vol. 11, pp. 1-33

40. A. Muñoz-Villamizar, E. Solano, C. Quintero-Araujo, J. Santos, Sustainability and digitalization in supply chains: a bibliometric analysis, Uncertain Supply Chain Manag. 7 (2019) 703-712
41. R. Shawahna, Q. Nairat, Research productivity in the field of physical exercise and epilepsy: a bibliometric analysis of the scholarly literature with qualitative synthesis, Epilepsy Behav. 121 (2021) 108058.

42. M. Smith, Y. Sarabi, What do interlocks do revisited - a bibliometric analysis, Manag. Res. Rev. 44 (2021) 642-659

43. B.A. Niccum, A. Sarker, S.J. Wolf, M.J. Trowbridge, Innovation and entrepreneurship programs in US medical education: a landscape review and thematic analysis, Med. Educ. Online 22 (2017) 1360722

44. S. Verma; N. Yadav, Past, present, and future of electronic word of mouth (EWOM), J. Interact. Mark. 53 (2021) 111-128

45. H.D. White, B.C. Griffith, Author cocitation: a literature measure of intellectual structure, J. Am. Soc. Inf. Sci. 32 (1981) 163-171

46. C.H. Hsiao, C. Yang, The intellectual development of the technology acceptance model: a co-citation analysis, Int. J. Inf. Manag. 31 (2011) 128-136

47. K.-Y. Tang, C.-C. Tsai, T.-C. Lin, Contemporary intellectual structure of CSCL research (2006-2013): a co-citation network analysis with an education focus, Int. J. Comput. -Support. Collab. Learn. 9 (2014) 335-363

48. N. Hernández-Sellés, P.-C. Muñoz-Carril, M. González-Sanmamed, Computer-supported collaborative learning: an analysis of the relationship between interaction, emotional support and online collaborative tools, Comput. Educ. 138 (2019) 1-12

49. B. Berman, 3-D printing: the new industrial revolution, Bus. Horiz. 55 (2012) 155-162

50. J. Kietzmann, L. Pitt, P. Berthon, Disruptions, decisions, and destinations: enter the age of $3-\mathrm{D}$ printing and additive manufacturing, Bus. Horiz. 58 (2015) 209-215

51. D.J. Teece, Business models, business strategy and innovation, Long Range Plann. 43 (2010) 172-194

52. M.W. Johnson, C.M. Christensen, H. Kagermann, Reinventing your business model, Harv. Bus. Rev. 86 (2008) 57-68

53. J.O. Montes, Impacts of $3 \mathrm{D}$ printing on the development of new business models, in Proceedings of the 2016 IEEE European Technology and Engineering Management Summit (E-TEMS) (2016) pp. 1-9

54. T. Rayna, L. Striukova, J. Darlington, Co-creation and user innovation: the role of online 3D printing platforms, J. Eng. Technol. Manag. 37 (2015) 90-102

55. C. Weller, R. Kleer, F.T. Piller, Economic implications of 3D printing: market structure models in light of additive manufacturing revisited, Int. J. Prod. Econ. 164 (2015) 43-56

Cite this article as: Thywill Cephas Dzogbewu, Nathaniel Amoah, Samuel Korateng Fianko, Sampson Afrifa Jnr, Deon de Beer, Additive manufacturing towards product production: a bibliometric analysis, Manufacturing Rev. 9, 1 (2022) 